TITLE:

\title{
A CONTRIBUTION TO THE BIOLOGY OF THE BLACK ROCKFISH, SEBASTES INERMIS CUVIER ET VALENCIENNES
}

AUTHOR(S):

Harada, Eiji

CITATION:

Harada, Eiji. A CONTRIBUTION TO THE BIOLOGY OF THE BLACK ROCKFISH, SEBASTES INERMIS CUVIER ET VALENCIENNES. PUBLICATIONS OF THE SETO MARINE BIOLOGICAL LABORATORY 1962, 10(2): 307-361

ISSUE DATE:

1962-12-31

URL:

http://hdl.handle.net/2433/175307

RIGHT: 


\title{
A CONTRIBUTION TO THE BIOLOGY OF THE BLACK ROCKFISH, SEBASTES INERMIS CUVIER ET VALENCIENNES ${ }^{\text {i) }}$
}

\author{
EIJI HARADA \\ Department of Zoology, University of Kyoto
}

With 29 Text-figures and 7 Tables

\section{Introduction}

Evidence has been established that certain fishes, when they are young, occur in the Zostera belt in considerable number and mostly disappear from there as they grow (OHshima, 1954 ; Fuse et al., 1956; Fuse et al., 1959; Hatanaka and IIzUKA, $1962 a, b, c$; FUSE, $1962 a, b$ ). The most notable of them are Lateolabrax japonicus, Hexagrammos otakii, Agrammus agrammus, Sebastes inermis, and Sebastes oblongus. Their colonization and emigration concur generally with the increase and decrease of small phytal animals in the Zostera belt, and they are supposed to aggregate there to feed on these small animals on Zostera as well as to be sheltered and protected from the enemies. It has also been pointed out that some of them are inhabiting other areas as well, and Sebastes inermis, for instance, is quite abundant in the rocky area (HAT ANAKA and IIzukA, 1962b), occupying it from the younger on to the adult stage (FusE, $1962 b$ ). Obviously these two areas or major habitats are utilized by a fish Sebastes inermis equally at a certain time and differently at other. In other words, in the manner in which the fish lives changes occur, with which, together with that of other organisms, its relations with other beings and the significance of a community to, its life is varying.

Although there are accumulations of detailed knowledge and information concerning various aspects of life of fish and of the community it belongs to, there has been still little research on the life history of fish from the developmental and synecological points of view. Important aspects of ecology of a fish, for instance, distribution, migration or food, are treated rather separately from phases of its life history and its surrounding biotic communities. If the changes in life of a fish and its diversity, say the habitats of Sebastes inermis, are closely connected with the development of phases of life history and the transformation

1) Contributions from the Seto Marine Biological Laboratory, No. 394.

Publ. Seto Mar. Biol. Lab., X (2), 1962. (Article 17) 
of surrounding communities, this might necessitate to observe the way of living at each particular epoch in relation to the process of life history and the interrelationships within a community. This, in turn, would postulate that elucidation of life histories of constituent organisms is one of the primary requisites for an understanding of the dynamics and structure of a living community, though the community approach is certainly valuable in obtaining the general picture of a whole community.

On the basis of the results of the survey on the Zostera and Sargassum belts, obtained so far through collaboration of the group of participators, the present investigation has been directed towards an understanding of ecology and life history of Sebastes inermis by piecing morphological changes and reciprocal interaction in the community at each stage of life together. Particularly the larval and juvenile life have been paid much attention.

The black rockfish, or "Mebaru" in Japanese, Sebastes inermis Cuvier et VALENCIENNES, is a member of the familiy Scorpaenidae, which comprises under the present system of nomenclature 8 subfamilies and 21 genera in Japan. This species has been sometimes placed in the genus Sebastodes GILL, which has been regarded distinct from the genera Sebastichthys GiLl and Sebastes Cuvier. However, Matsubara (1943) made a comprehensive anatomical and taxonomical study of the scorpaenoid fishes and consolidated the two Pacific genera Sebastodes and Sebastichthys into the Atlantic genus Sebastes.

Practically little has been known concerning the whole progression of life of Sebastes inermis. Histological observations on maturation and reproduction cycle of the species have been reported in detail by Mizue (1957, 1958 $a, b, 1959 a, b, c)$ and Mio (1960, 1961). Hatanaka and Iizuk A (1962c) have studied growth and food of the species in captivity. The descriptions on the morphology of the larval and juvenile stages are briefly given by NAKAmura (1934) and UCHIDA (1943). As to the ecology of species, the fragmentary accounts have been published by Ohshima (1954), Fuse et al. (1956), Kitamori and Kobayashi (1958), Krtamori, Nagata and Kobayashi (1959), Fuse et al. (1959), Kikuchi (1961), and HATANAKA and IizukA $(1962 a, b, c)$. Few are, however, available particularly on the ecology of the larvae and juvenile.

Other members of the genus Sebastes in Japan have been paid little attention, save the subsidiary informations from the studies of the communities in various areas. Descriptions of the larvae and juvenile have been presented for Sebastes schlegeli HilgendorF and Sebastes pachycephalus pachycephalus TEMMINCK et ScHLEGEL by INABA (1931), for Sebastes pachycephalus nigricans (SCHMIDT) by Fujita (1957), for Sebastes hubbsi (Matsubara) by NAKAmura (1936) and Shojima (1958), and for Sebastes pachycephalus pachycephalus by Siokawa and Tsukahara (1961). In the North Atlantic and European areas, Templeman (1959) has investigated the distributions of Sebastes marinus, compristing two subspecies, and 
Sebastes viviparus, and TANING (1949) has shown the wide extension of breeding area of Sebastes marinus. LAMBERT (1960) has described the variations in food of Sebastes marinus. The larvae of Sebastes in the North Atlantic has been the object of the intensive survey, and SteEle (1957), Einarsson (1960), Henderson (1961 $a, b)$, HANSEN and ANDERSEN (1961), etc., have reported on the distribution and abundance of the larvae and juveniles of Sebastes marinus. Other species have been referred very little.

\section{Acknowledgements}

I am deeply indebted to Professor D. MIYADI and Professor S. MORI for their encouragements and advices given to me during the course of the study, and to Dr. T. HABE, now at the National Science Museum, Dr. S. Fuse of the Seto Marine Biological Laboratory, Dr. T.. Mrura, now at the Otsu Hydrobiological Station, and Mr. R. Okuno, now at the Suma Aqurium of Kobe City, for their helpful suggestions and co-operation in the field. I am also indebted to Dr. A. Murakami, Mr. A. Inoue, Mr. S. Nishina and Mr. S. Takamori of the Naikai Regional Fisheries Research Laboratory, and to my colleagues at the Department for the assistance in collecting materials. My thanks are also due to Professor H. Utinomi, Dr. T. Tokioka and Dr. I. Yamazi of the Seto Marine Biological Laboratory, Dr. K. NAGATA of the Naikai Regional Fisheries Reseach Laboratory and Mr. S. Takamatsu of our Department, in connexion with the taxonomy of various groups of animals.

Most of the materials dealt with in the present paper were obtained during the survery of the Zostera and Sargassum belts in the Kasaoka Bay, financed by a grant-in-aid from the Fisheries Agency of the Ministry of Agriculture, and during the survey of the fisheries and marine food animals and seaweeds in the Naka-no-umi District at the request of the Shimane Prefectural Government, which are gratefully acknowledged.

\section{Methods: Gears and Their Ecological Usefulness}

Most of the methods and gears employed in this investigation have been well described and illustrated by FusE (1962a,b), so only the particular constructions and specifications of the gears and the ways they were operated are necessary to be indicated briefly here, since the interpretation of the data from these measures are subject to considerable limitations in some cases, which are imposed by the gears. On the other hand, it should be important to consider their reliability as collecting measures in the ecological survey.

(1) The tow net

The tow nets were used to collect pelagic larvae of fish as well as to 
sample plankton organisms in the regions. Two of them, used exclusively for collecting fish larvae, were made with filtering gause of 40 and 11 meshes to the inch, fitted to the opening rings of 0.5 and $1.5 \mathrm{~m}$ in diameter respectively. A small flowmeter was fitted also to the ring at the centre. They were towed by a motored boat mostly horizontally on surface and at a depth of about $10 \mathrm{~m}$ or at bottom layer if water was shallower than $10 \mathrm{~m}$. The duration of towing was various according to topography of localities; however, the speed was regulated to cover approximately $30 \mathrm{~m}$ per minute and eventually the volume of water filtered at each haul was estimated to be $30 \mathrm{~m}^{3}$ for the $0.5 \mathrm{~m}$ diameter net and $500 \mathrm{~m}^{3}$ for the $1.5 \mathrm{~m}$ diameter one. In the case of deeper hauls, the nets travelled from the depth filtering water on its way up. The errors caused could be minimized by extending the distance in comparison to the depth as well as by a practical attempt to let the agile plankton animals escape as far as possible by slowing down the speed of hauling through the vertical course. The former is useful only to collect early larvae unable to swim swiftly, and the latter, which aimed to catch late larvae and juveniles, did not work satisfactorily and catches were very few.

A mid-water trawl for collecting juvenile fish has been proposed by Kato and Kurohiji (1960), who suggest that a net should be towed at higher speed to catch the juvenile of good swimming power. BRIDGER (1958) has also pointed out the exceeding efficiency of a modified high-speed tow net for catching the fish larvae. But these types of net were not used in the present investigation.

The plankton was collected with a net of the filtering gauze of 130 meshes to the inch, fitted to the $25 \mathrm{~cm}$ diameter ring. This was towad vertically from the bottom to the surface.

\section{(2) The beam trawl}

The beam trawls of small size were worked on muddly and sandy bottoms and in the Zostera belt. One used in the Kasaoka Bay was with $2 \mathrm{~m}$ beam and the other in the Naka-no-umi region with $3 \mathrm{~m}$ beam. The meshes were both large enough to alow the escapement of small larvae of fish, but these were fairly good for the juvenile and small fishes, and the catches were sufficienly quantitative.

\section{(3) The shank net}

In the Sargassum belt on the rocky reef a shank net was efficiently dragged. It had an iron beam on the bottom, bounded by a curved iron bar to form the semi-circular mouth. The breadth and the height of the mouth frame were 1 and $0.5 \mathrm{~m}$ respectively. Although the net was useful on bottom of such kind where no alternative measures could be worked, the catch by this net was far from being quantitative, for the net had to be hauled a little up whenever it stuck against rocks, and fishes could escape had they sufficient attention to do so. 
(4) The filter net

The Kobukuro-ami and the Fukuro-machi-ami are both fundamentally the filter nets. The former fished in the Naka-no-umi region was set between two poles near the bottom and of $4 \mathrm{~m}$ by 2 at the mouth approximately. The latter operated in the Seto Inland Sea for the sand-lance fishery was $15 \mathrm{~m}$ by 6 at the mouth. This was sunken to the bottom on the straits and was fished on two large anchors keeping its mouth open. These can be regarded as the quantitative measures of catching animals which are drifting on currents, at the same time they are useful to some extent for analysing mevements of some fishes and prawns.

(5) The guiding barriers

The Masu-ami is a kind of guiding barriers with a leader and square pound supported on poles and extending from the bottom to above the water surface, for which KazihaRA et al. (1958) have given detailed descriptions. The size of the guiding barriers was various according to topography. Being this gear dependent its effectiveness on active movement and migration of animals, the comparison of catches for each species affords clues to elucidate the activity of animals in nature, though the data gained are not directly convertible to the expression of population size.

(6) The trammel

The trammels or anchored gill-nets were used to catch large fishes particularly in the Sargassum belts. A sheet of the net was $20 \mathrm{~m}$ long and $1.2 \mathrm{~m}$ high. This gear, although very effective for reef fishes, is not a quantitative measure, but the activity of fishes, by day and by night for instance, can be deducted from the catches.

(7) The coracle net

The coracle net of nearly the same size to the trammels were also fished in the Sakai Channel. The catch by this net is sufficiently quantitative for the bottom fishes, if the distance of drift was accurately measured.

(8) Diving

Diving with the scuba was a direct means to observe the behaviour of fishes and other animals, to count and to collect them. However, the standardized methods of underwater observation and noting down events observed had not been fully established yet, and unfortunately the results gained failed to be treated statistically. While diving the submerged plants were reaped quantitatively by using a quadrate basket, together with phytal animals associated with them.

(9) Treatment of materials

The animals thus caught with these gears were counted by species, measured and weighed individually. The stomachs of fishes were opened and the contents 
were examined and identified, if possible, to the species with numbers occurred. Out of the data obtained those concerning Sebastes inermis are treated in detail in the present paper. For the plankton the volumes were measured by sedimentation method and only the subsamples of various proportions were rendered for examination of composition.

(10) Environmental factors

The temperature, chlorinity, transparency and oxygen content of water were taken, and for the rest of possible factors, otherwise measured by the cooperating scientist, other reports should be referred.

\section{General Features of the Regions}

The results, particularly regarding the pelagic larvae, are mostly obtained from the Kasaoka region. During the course of the survey of the Zostera and Sargassum belts from 1952 to 1957 , our observations were concentrated to the Kasaoka Bay and its approaches, which was situated on the northern fringe of the middle part of the Seto Inland Sea. But after the investigation on Sebastes larvae was initiated in 1957, the observations were extended to cover the adjacent waters of small islands half way down to the middle of the main sea, which were lying on a line from Kasaoka to a point projecting on the north coast of Shikoku (Fig. 1). This part of

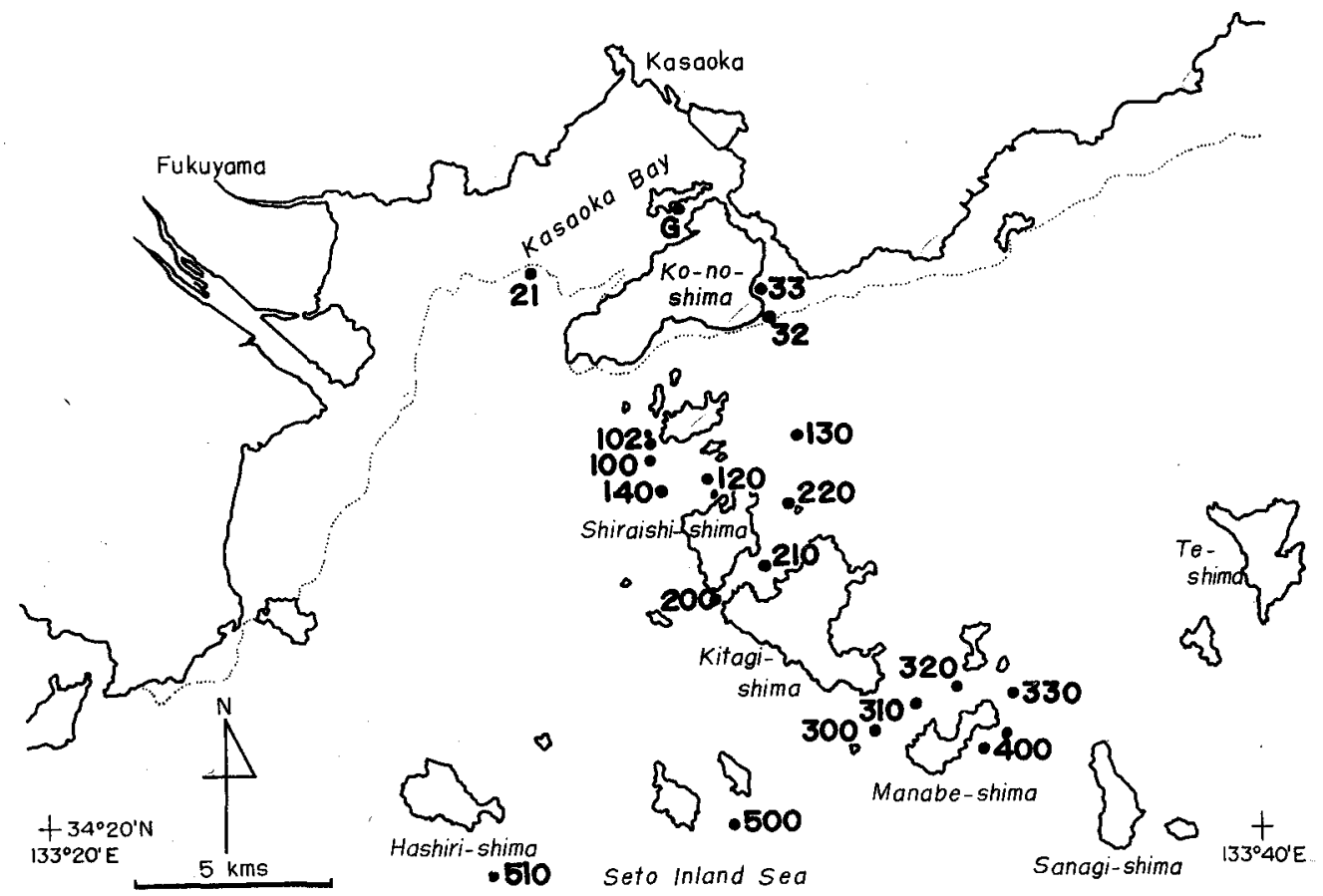

Fig. 1. The Kasaoka region, showing the positions of sampling stations. 
the sea is bounded on the north by the south coast of western Honshu, on the south by the north coast of Shikoku, and on the east and west by the scattering small islands. It is thus well sheltered from the Pacific, however, since the tidal currents are strong, water from the Pacific flows well on to there through the Bungo and Kii Straits. The maxima of the tidal currents in this part, read from the navigation chart, are around 1 knot, but stronger currents are often observed in between islands.

The depth is for the most part more than $20 \mathrm{~m}$, but is less than $10 \mathrm{~m}$ for the Kasaoka Bay, and the bottom is fairly uniform and is largely of soft mud.

In the shallow waters along the coasts of the bays and islands, Zostera grows thickly at places (FUSE, $1962 a$; KITA and HARAdA, 1962), and the maximum standing crop of $2,352 \mathrm{gr}$ wet weight per square metre in winter is given for the inner part of the Kasaoka Bay by KITA and HaradA (1962). The Zostera belt extends rather deeper when it occurs along the sandy shores of island in the middle of the sea, and grows longer blades.

The islands in the middle of the sea are characterized much more by granite boulders and rocks on the shores. The Sargassum belt is the dominant vegetation occupying these areas as well as underwater rock outcrops. It flourishes in water and a part of it may survives through summer, as is seen in Fig. 7.

These areas afford favorable and complex habitats for animals and small algae, and sustain various biotic communities (Petersen, 1911, 1918; Colman, 1939;

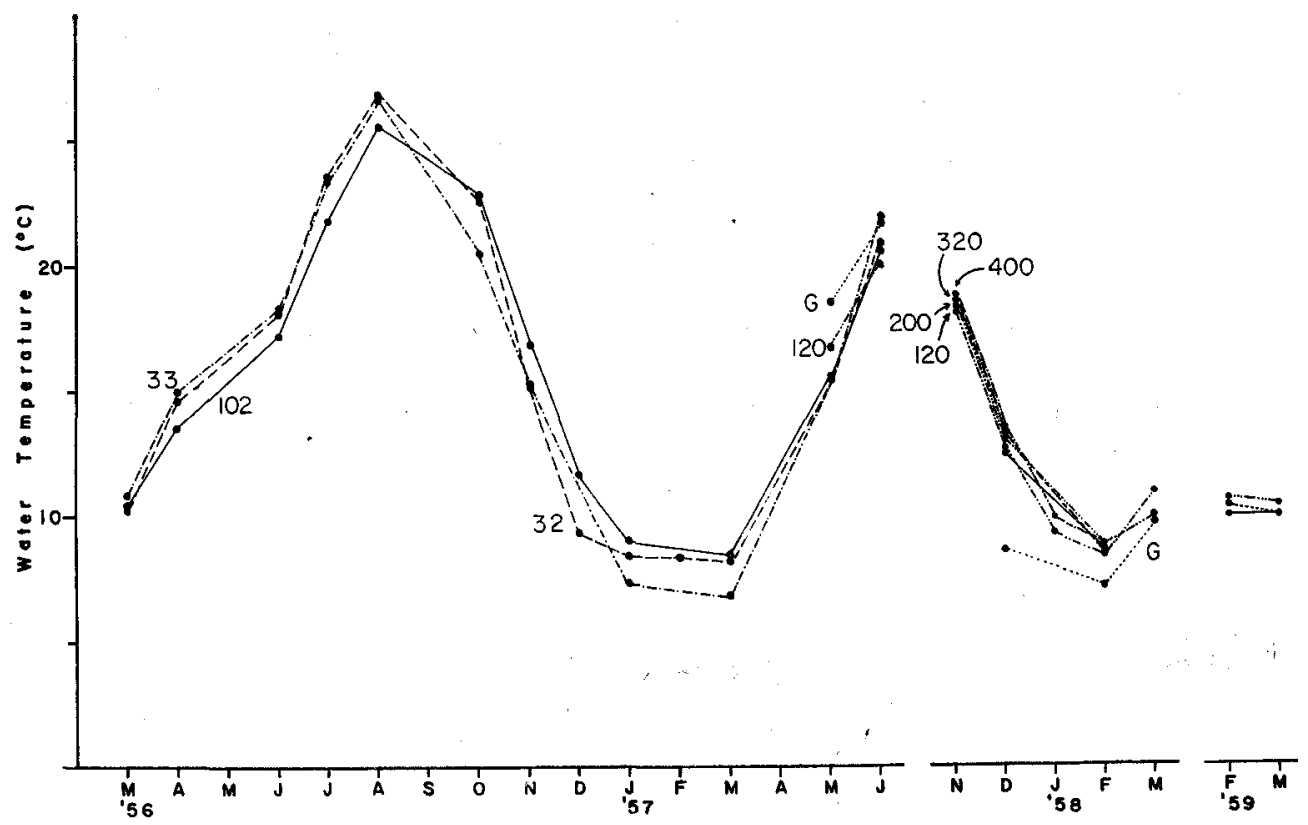

Fig. 2. Seasonal fluctuations of the water temperature in the Kasaoka region during the period of investigation. 
Ohshima, 1954; Fuse et al., 1956; Kitamori and Kobayashi, 1958; Kitamori, Nagata and Kobayashi, 1959; Fuse et al., 1959; Kikuchi, 1961 ; Hatanaka and IIZUKA, $1962 a, b$ ).

The trawlers for shrimps and bottom fishes and the sand-lance fishery are most heavily operating in this region. The landings of the black rockfish is representing usually less than $1 \%$ of the total of commercial fisheries in weight in the Kasaoka Fishery District, while it accounts for more than $25 \%$ of the landings by the reef trammels. Its landing in 1957 (fiscal year) was $46,125 \mathrm{~kg}$ for this district.

The hydrographic conditions of the Kasaoka Bay is described in detail by Murakami (1954), and the data of some environmental features during the period
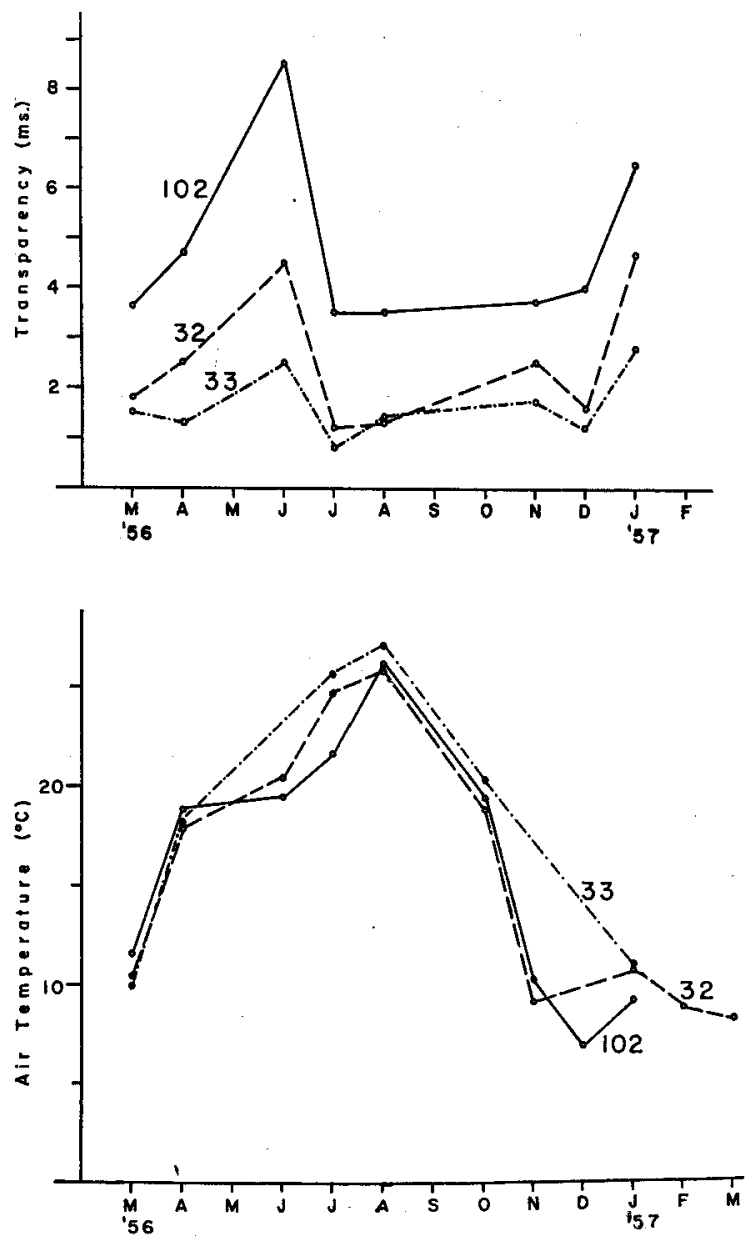

Fig. 3. Seasonal fluctuations of the water transparency and air temperature in the Kasaoka region. 
of the investigation are presented in Figs. 2-3. As can be seen, there are less remarkable differences in water temperature over the whole region if compaired with the seasonal variations. The chlorinity there keeps around 17\%, equivalent to $30.72 \%$ of salinity, with little geographical variations, except the heavy rainy seasons and stomy weeks.

A part of the results, on which this paper is based, are also obtained in the Naka-no-umi region (Fig. 4). Naka-no-umi, a nearly detached brackish arm of

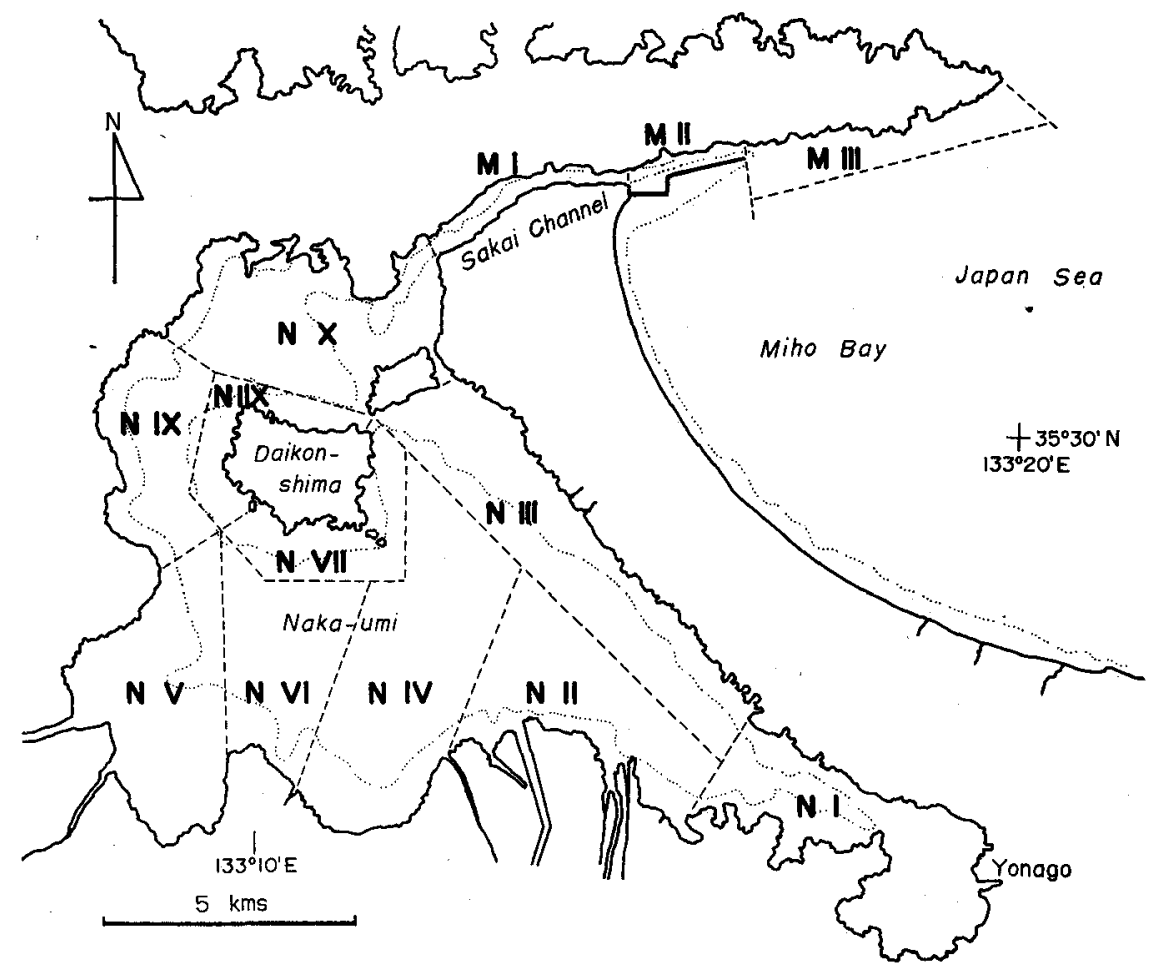

Fig. 4. The Naka-no-umi region and its statistical subregions.

the sea, is communicating on one end with the Miho Bay on the Japan Sea coast of western Honshu through the narrow Sakai Channel and on the other with the Shinji Lake, almost freshwater, through the Ohashi River. Tidal range is very small in this district, $0.3 \mathrm{~m}$ in an average, aud the surface chlorinity drops from $18 \%$, equivalent to $35.52 \%$ of salinity, in the Miho Bay to $9 \%$, equivalent to $16.28 \%$ of salinity, in Naka-no-umi. The surface temperature shows fair difference in winter between Naka-no-umi and the Miho Bay, but not so much is summer. Seasonal fluctuations of some hydrographic features are shown in Fig. 5.

In this region, too, Zostera is predominating on the muddy bottom, specially in Naka-no-umi. The whole of Naka-no-umi is almost level, less than $8 \mathrm{~m}$ in depth 

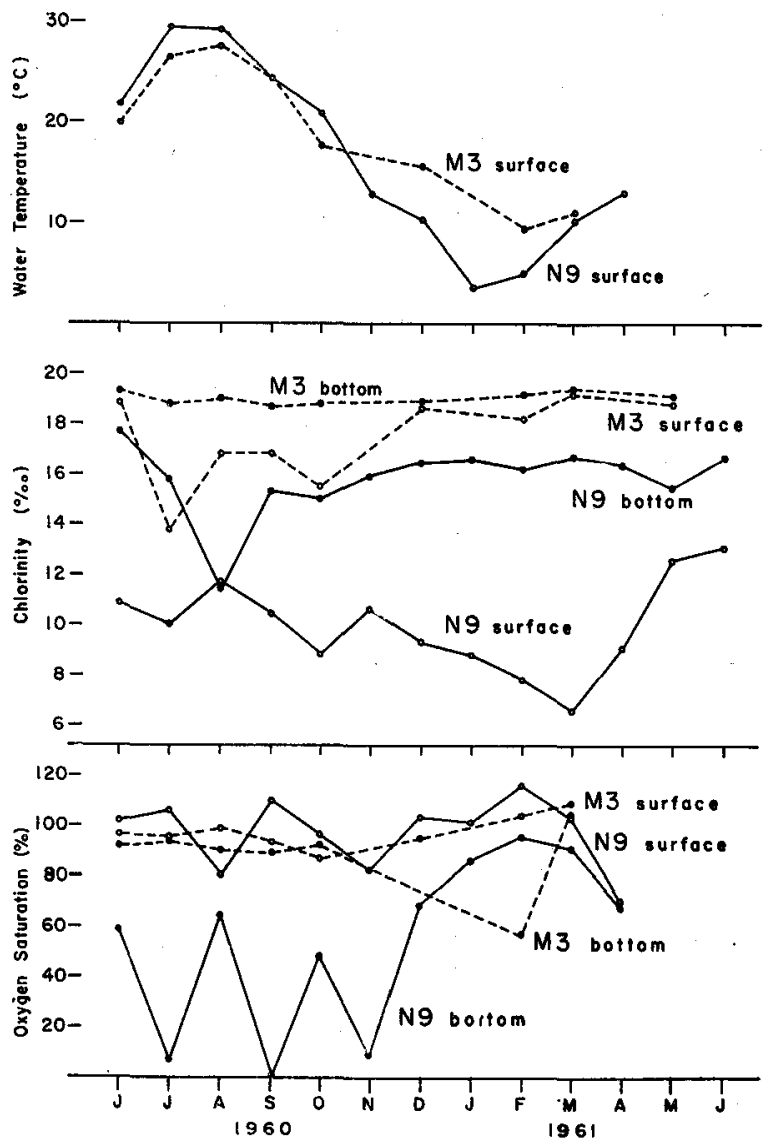

Fig. 5. Seasonal fluctuations of the water temperature, chlorinity and oxygen content in the Naka-noumi region.

except an abrupt depression near the seaward entrance. In the Miho Bay, the bottom slopes gently from a long sand beach on the west and south, but is very steep on the north along the rocky shore of the Zizosaki Point, and reaches the depths of 30 to $40 \mathrm{~m}$ in the middle. Sargassum is covering the rocks anywhere in the waters, particularly outstanding in the northern portion of Naka-no-umi and around the Zizosaki Point.

The records of catches of Sebastes inermis by the trammels in the Tomioka regions were afforded by the Amakusa Marine Biological Laboratory by courtesy of Dr. T. HABE. The Tomioka Bay is situated on the northern tip of the Amakusa Island, by which the Ariake Sea is bounded on the west. The growths of Zostera on the shallow muddy bottom and of Sargassum on the rocks are well developed. 


\section{Habitat}

The black rockfish occurs commonly in almost all of coastal waters of Japan, from Hokkaido to Kyushu, either on the Pacific coasts or on the Japan Sea coasts. Some of scorpaenoid fishes other than Sebastes inermis were also caught during the survey. Sebastiscus marmoratus (Cuvier et Valenciennes) and Sebastes oblongus GÜNTHER were most numerous in both the Kasaoka and the Naka-noumi region. Sebastes longispinis (MATSUBARA) in the Kasaoka region and Sebastes schlegeli HILGENDORF in the Naka-no-umi region were very rarely collected.

As has been mentioned for the commerical trammel fishery in the rocky areas in the Kasaoka region, the scorpaenoid fishes are the important objectives. The relative abundance of the landings of Sebastes inermis, Sebastes oblongus, and Sebastiscus marmoratus at the Kasaoka Fishery Market are summarized in Table 1.

Table 1. Seasonal fluctuations of the landings of three scorpaenoid fishes at the Kasaoka Fishery Market, in the years 1956-1957.

Ht: abundant ; H : common ; + : present ; $r$ : rare

\begin{tabular}{l|c|c|c|c|c|c|c|c|c|c|c|c|}
\hline \multicolumn{1}{c|}{ Month } & Feb. & Mar. & Apr. & May & June & July & Aug. & Sept. & Oct. & Nov. & Dec. & Jan. \\
\hline Sebastes inermis & $+H$ & + & + & - & $\mathrm{r}$ & $\mathrm{r}$ & $\mathrm{r}$ & - & + & +1 & + & H \\
Sebastes oblongus & + & + & $\mathrm{r}$ & - & $\mathrm{r}$ & $\mathrm{r}$ & $\mathrm{r}$ & - & + & + & + & + \\
Sebastiscus marmoratus & $\mathrm{r}$ & + & + & - & $\mathrm{r}$ & $\mathrm{r}$ & $\mathrm{r}$ & - & + & +1 & + & + \\
\hline
\end{tabular}

(1) The adult

The adult black rockfish is fished mostly in the offshore part of the region and is very scarce in the inner part of the bay. This is also so in the Naka-noumi region, as shown in Fig. 6. This may be largely due to the poor development of the rocky reefs in the inshore part.

The trammels are usually set in and around rocky reefs. Examination of the nets as they were lifted up into a boat revealed that most of the black rockfish were caught in group rather than individually on the nets and this happened in almost all occasions at certain definite positions of reefs. While diving Sebastes inermis was observed in the rocky areas inhabiting from close to the low tide mark down to $15 \mathrm{~m}$ depth in both the Kasaoka and Naka-no-umi regions. However, judging from the data of catches by the trammels, the range of distribution may be extending further downward. In most cases the adults were aggregating, 10 to 20 at a place, in rock crevices and holes or were lurking underneath the boulders in smaller group or individually, but were seldom seen cruising on shoal. The favorable underwater crevices were usually present at these positions where the black rockfish was caught in group.

Under or among rocks were also found Sebastiscus marmortus and occasionally Sebastes oblongus, but, differing from Sebastes inermis, they were always reposing on rocks and not hovering. Agrammus agrammus (TемMinck et SCHLEGEL) and 


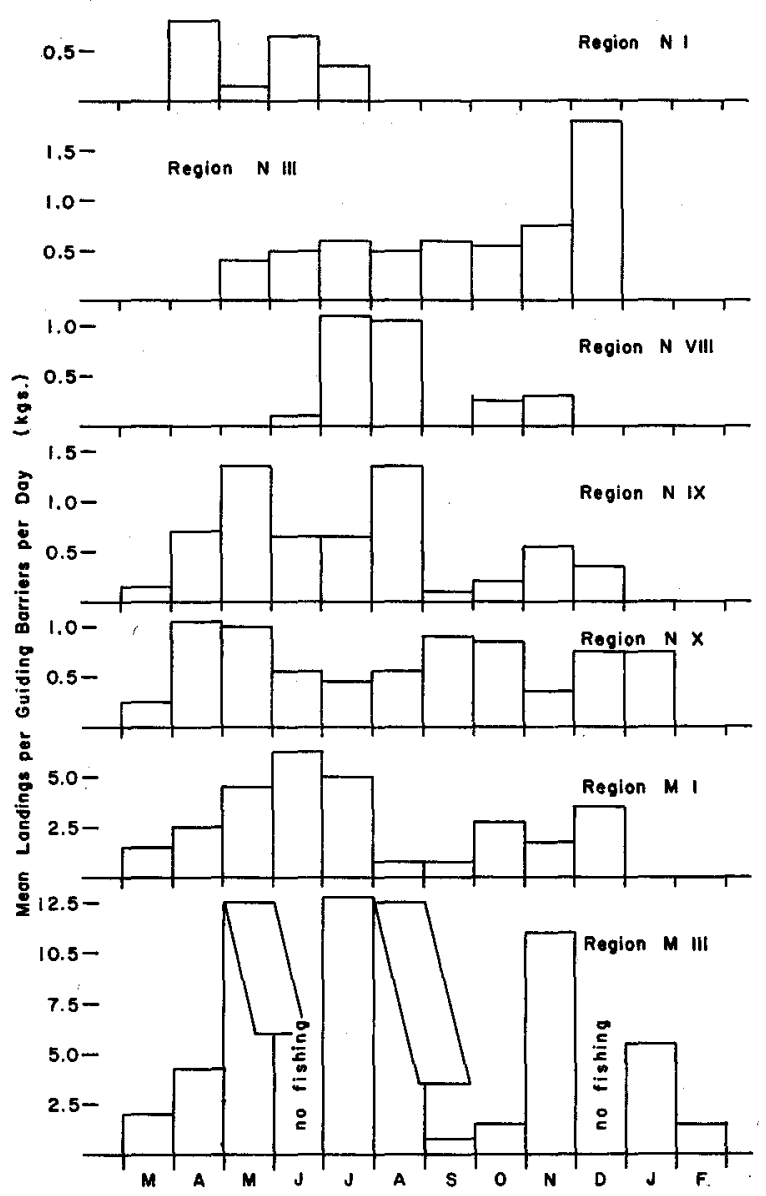

Fig. 6. Monthly average landings in weight per guiding barriers-day in each subregion of the Naka-no-umi region.

Hexagrammos otakii JoRDAN et STARKS were commonly seen resting upon rocks. In the peripheral parts of reefs Halichoeres poecilopterus (TEMmINCK et SCHLEGEL) were numerous. The common sea-stars, Asteriana pectinifera (MüLLER et TROsCHEL) and Asterias amurensis (LüTKEN), edible sea cucumber, Stichopus japonicus Selenka, sea-fan, Comanthus pervicirra (J. Müller), and sea urchin, Anthocidaris crassospina (A. AGASSIZ) were predominating large echinoderms crawling on rocks. Beneath the boulders and rocks were often found numerous brittle stars, mostly Ophiomastix mixta LÜTKEN, in aggregation. In the Naka-no-umi region, Omobranchus elegans (STEINDACHNER) and gobid fishes were abundant among rocks, and Charybdis japonicus A. M. EDwards and Portunus pelagicus (LinNe) were the predominant large crustaceans. There were, however, few or no other fishes 
utilizing the same microhabitats as that of Sebastes inermis, except some of Mylio macrocephalus (BAsilewsky) and Chromis notatus (Temminck et Schlegel).

The rocks were usually covered with thick growths of Sargassum, especially in winter and spring. The vegetations of Sargassum harboured considerable populations of small crustaceans, mollusks and fishes (Fig. 7 and Tables 2-3). The amount and composition of these phytal animals varied remarkably from season to season. The amphipods, the dominant species of which were different between the Kasaoka and the Naka-no-umi region, were generally abundant in spring and diminished in summer. While caprellids were rather few in Nakano-umi, there were observed rich populations of Caprella danilevskii CzERNIAwski on Sargassum in the Miho Bay in March 1962. In the Kasaoka region, two prawns, Palaemon serrifer (STIMPson) and Heptacarpus geniculatus (STIMPson), were very much numerous in winter, whereas another prawn, Palaemon ortmanni Rathbun, increased in summer. Thus, the phytal animals as a whole in the Sargassum belt started decreasing in amount in early summer and reached to the lowest in late summer. The representative fishes of the community were Hypodytes rubripinnis (Temminck et Schlegel), Rudarius ercodes Jordan et Fowler and Pseudoblennius

Table 2. Relative abundance of phytal animals on Sargassum and Zostera during 1956.

\begin{tabular}{|c|c|c|c|c|c|c|c|}
\hline \multirow{3}{*}{ Organism } & \multirow{3}{*}{$\begin{array}{l}\text { Locality } \\
\begin{array}{l}\text { Vegetation } \\
\text { (dominant) }\end{array} \\
\text { Date }\end{array}$} & \multicolumn{4}{|c|}{ Station 102} & \multirow{2}{*}{\multicolumn{2}{|c|}{ 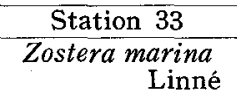 }} \\
\hline & & \multicolumn{2}{|c|}{ Sargassum } & \multicolumn{2}{|c|}{$\begin{array}{l}\text { serratifolium } \\
\text { C. Agardh }\end{array}$} & & \\
\hline & & $\begin{array}{c}\text { March } \\
27\end{array}$ & $\begin{array}{l}\text { April } \\
25\end{array}$ & $\begin{array}{c}\text { August } \\
21 \\
\end{array}$ & \begin{tabular}{|c|} 
November \\
21
\end{tabular} & $\begin{array}{c}\text { March } \\
27\end{array}$ & $\begin{array}{c}\text { November } \\
21\end{array}$ \\
\hline \multicolumn{2}{|c|}{ Apherusa bispinosa (BATE) } & + & & $\mathrm{r}$ & & & \\
\hline \multicolumn{2}{|c|}{ Pleustes panopla (KROYER) } & $t$ & & & & & \\
\hline \multicolumn{2}{|c|}{ Pontogeneia sp. } & & H & & & & \\
\hline \multicolumn{2}{|c|}{ Paradexamine barnardi SCHEARD } & $\mathbf{r}$ & & & & & \\
\hline \multicolumn{2}{|c|}{ Ampithoe lacertosa BATE } & $H$ & & & & & $\mathbf{r}$ \\
\hline \multicolumn{2}{|c|}{ Jassa falcata (MoNTAGU) } & + & & & $\mathrm{r}$ & & \\
\hline \multicolumn{2}{|c|}{ Corophium uenoi STEPHENSEN } & & $\mathbf{r}$ & & & & \\
\hline \multicolumn{2}{|c|}{ Podocerus cristatus (THOMPsoN) } & + & & $\mathrm{r}$ & & & \\
\hline \multicolumn{2}{|c|}{ Caprella aequilibra $\mathrm{SAY}$} & & + & & & & \\
\hline \multicolumn{2}{|c|}{ Caprella danilevskii CZERNIAWSKI } & & $\mathrm{r}$ & & & & $\mathbf{r}$ \\
\hline \multicolumn{2}{|c|}{ Caprella decipiens MAYER } & \# & H & H & H & & \\
\hline \multicolumn{2}{|c|}{ Caprella kröyeri DE HAAN } & & & & & H & \\
\hline \multicolumn{2}{|c|}{ Caprella linearis (LINNÉ) } & $\mathbf{r}$ & & & & & \\
\hline \multicolumn{2}{|c|}{ Caprella monoceros MAYER } & H & Ht & + & H & & H \\
\hline \multicolumn{2}{|c|}{ Caprella scaura TEMPLETON } & & & & & & H \\
\hline \multicolumn{2}{|c|}{ Caprella scaura f. diceros MAYER } & H & H & $\mathrm{r}$ & & & \\
\hline \multicolumn{2}{|c|}{ Caprella subinermis MAYER } & $\mathbf{r}$ & & & & & \\
\hline \multicolumn{2}{|c|}{ Spirorbis foraminosus MoORE et BuscH } & & & & $H$ & & \\
\hline \multicolumn{2}{|l|}{ Nematods } & & & H & + & & \\
\hline \multicolumn{2}{|c|}{ Total wet weight (grs.) per collection } & 25.40 & 3.58 & 0.80 & 90.00 & 59.98 & 0.27 \\
\hline
\end{tabular}



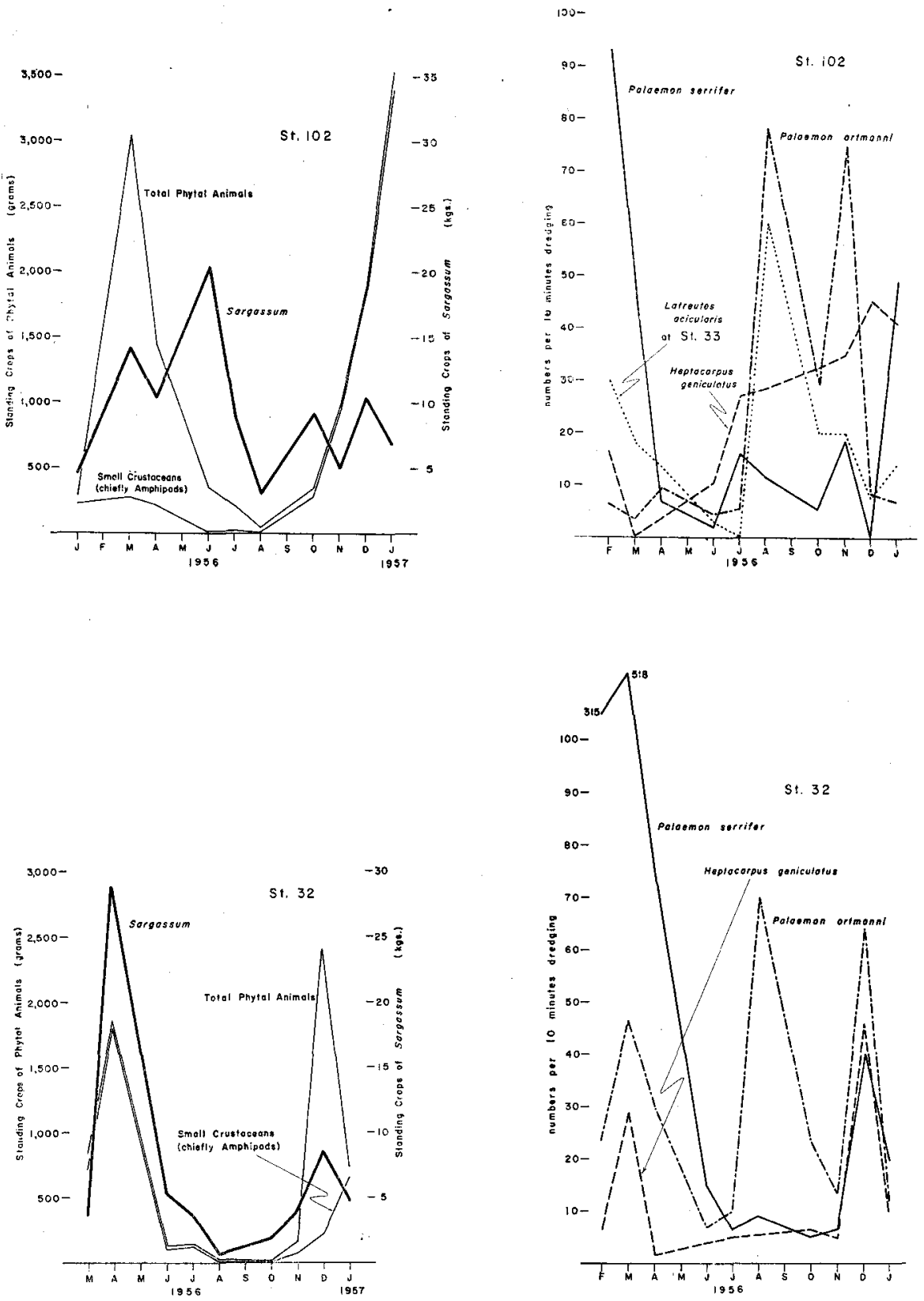

Fig. 7. Seasonal fluctuations of the amounts of Sargassum and phytal animals on it in the Kasaoka region. 
Table 3. Percentage composition by number of major constituents of phytal animals on Sargassum and Zostera during May to July 1961.

\begin{tabular}{|c|c|c|c|c|c|c|c|}
\hline \multirow{3}{*}{ Organism } & \multirow{2}{*}{$\begin{array}{l}\text { Locality } \\
\text { Vegetation } \\
\text { (dominant) }\end{array}$} & \multicolumn{3}{|c|}{$\begin{array}{c}\text { Akayama northern coast } \\
\text { of Naka-umi }\end{array}$} & \multicolumn{3}{|c|}{$\begin{array}{l}\text { Hanyu-southern coast } \\
\text { of Daikon-shima }\end{array}$} \\
\hline & & \multicolumn{3}{|c|}{$\begin{array}{r}\text { Sargassum serratifolium } \\
\text { C. Agardh }\end{array}$} & \multicolumn{3}{|c|}{ Zostera marina Linné } \\
\hline & Date , & $\begin{array}{l}\text { May } \\
20 \\
\end{array}$ & $\begin{array}{c}\text { June } \\
23\end{array}$ & $\begin{array}{c}\text { July } \\
15\end{array}$ & $\begin{array}{c}\text { May } \\
20\end{array}$ & $\begin{array}{c}\text { June } \\
24\end{array}$ & $\begin{array}{l}\text { July } \\
20\end{array}$ \\
\hline \multicolumn{2}{|l|}{ Pontogeneia sp. } & 90.1 & 94.3 & 92.0 & 50.0 & 88.7 & 56.1 \\
\hline \multicolumn{2}{|c|}{ Paradexamine barnardi SCHEARD } & & & & 18.2 & & \\
\hline \multicolumn{2}{|c|}{ Ampithoe valida SмIтн } & & & & & & + \\
\hline \multicolumn{2}{|c|}{ Caprella acutifrons LATREILLE } & & + & & + & & \\
\hline \multicolumn{2}{|c|}{ Caprella danilevskii CzERNIAWSKI } & + & + & & 25.0 & 7.5 & 20.7 \\
\hline \multicolumn{2}{|c|}{ Caprella scaura TEMPLETON } & & & & & + & \\
\hline \multicolumn{2}{|c|}{ Neomysis intermedia (CZERNIAVSKY) } & 8.5 & + & 3.2 & & & \\
\hline \multicolumn{2}{|c|}{ Polychaets } & & & & & & + \\
\hline \multicolumn{2}{|l|}{ Mysis larvae } & & 4.9 & 4.8 & & & 20.7 \\
\hline \multicolumn{2}{|c|}{ Total wet weight (grs.) per collection } & 210.46 & 182.70 & 32.37 & - & 66.50 & 26.30 \\
\hline
\end{tabular}

cottoides (RICHARDSON), and adult Sebastes inermis inhabiting among Sargassum blades were very few.

The fish and other animals in the rocky Sargassum area as the biotic community have been treated by Hatanak a and IizukA (1962 b) and Fuse (1962 $b$ ), and the compositions of them are almost similar to the present cases. These fishes are inhabiting in a same area or in a same major habitat and may be united closely together through food relations into the whole structure of the community, but their microhabitats and modes of life are, as has been suggested by OKuno (1956), so different and little actual and direct influences or interactions are possibly ascribable between them for the most part.

(2) The young

The young black rockfish, measuring from 2 to $6 \mathrm{~cm}$ in body length, has been paid much attention, particularly in connexion to the Zostera belt community. In general, the young appear in the Zostera belt during spring and summer (Ohshima, 1954 ; Fuse et al., 1959; Kikuchi, 1959 ; Hatanaka and Irzuk A, 1962 a), but afterwards only a small population are remaining there (KIKUCHI, 1959). This is true of the Naka-no-umi region and those caught in the inner part of Nakano-umi by the guiding barriers during spring and summer months were mostly the young (Fig. 6). A part of our unpublished data of catches by the guiding barriers, constructed amid a Zostera belt of St. 33, are summarized in Fig. 8. Young Sebastes inermis was caught in large numbers in April and June, but was few in catches of September and December when the number of species of fish in the belt increased. The disappearance of larger black rockfish from the Zostera belt is also noticed in the records of catches in the Tomioka region (Fig. 20). 


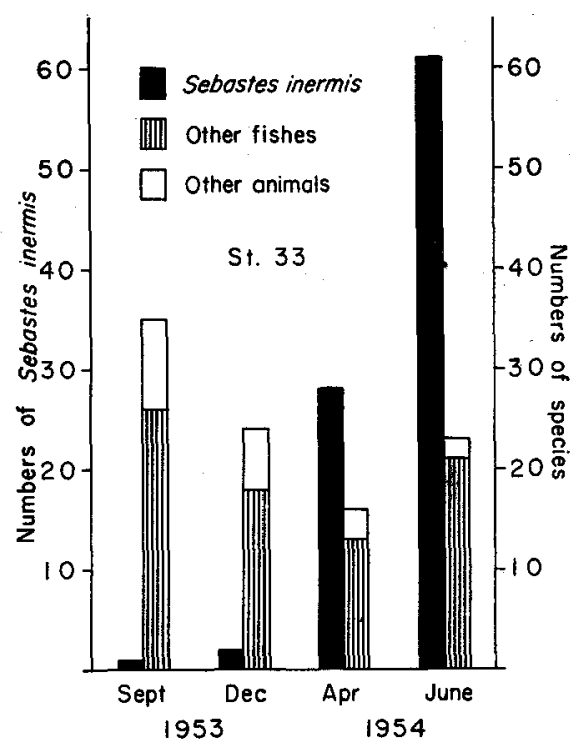

Fig. 8. Catches of Sebastes inermis per guiding barriers-day in a Zostera belt. The data are borrowed from the manuscript prepared for publication by Mr. R. Okuno, one of the collaborators, with his kind permission.

These results support the assumption that Sebastes inermis comes to the Zostera belt only during its younger stage and moves out after summer as it grows.

As has been reported by Fuse (1962 $a$ ), the amphipods were aboundant in the Zostera belt in late winter and spring, but almost disappeared in summer. The species composition of phytal animals on Zostera was different from that of the Sargassum belt and caprellids were relatively abundant. Like Palaemon ortmanni in the Sargassum belt, Latreutes acicularis ORTMANN increased in number in summer. Above all, Diala vitrea SOWERBY sometimes holded the overwhelming majority among them. Temnopleus toreumaticus (LESKE) was the large echinoderms dominating in the belt. Among fishes, Rhinogobius pflaumi (BLEEKER), Chaenogobius heptacanthus (HILGENDORF), Rudarius ercodes JORDAN et FowLER and Syngnathus schlegeli KAUP were abundant throughout a year.

The habitat of young black rockfish is by no means confined inshore to the Zostera belt. Although the young were failed to be fished by a shank net in rocky areas because of the deficiency of the effectiveness of the gear, it was confirmed by underwater observation that they were inhabiting in the offshore and inshore Sargassum belts. Contrary to the adult, the young were not utilizing the rock holes or crevices and were rather occupying in aggregation the room among and above Sargassum. A shoal observed at St. 102 in June was composed 
of more than 100 fishes, and the population density of the young among Sargassum blades near St. 400 was nearly 7 to 8 per square metre.

Occasionally the shoals of young black rockfish were observed cruising slowly or staying still alongside the rocks. When these youngs were chased by the observer, they always fled into the Sargassum growths, and in no occasion into rock crevices or holes. The youngs lodging among Sargassum were more or less solitary and were sheltering themselves by Sargassum blades. The population density of the solitary young in the Sargassum in the Naka-no-umi region was 0.5 to 1 per square metre.

In the Zostera belts, the shoals of the young, comprising 20 to 30 individuals, were often observed swimming above Zostera growths, there were solitary youngs abiding by the blades as well. The population density of the latter in the Nakano-umi region was generally smaller than in the Sargassum belt and was 0.1 to 1 per square metre.

Consequently, it is evident that the ways the young black rockfish is utilizing the Zostera and the Sargassum belt were basically identical. It is, however, still a matter of question whether the young discriminate these two vegetations. In many places in Naka-no-umi and around islands in the Kasaoka region, the scattered patches of Zostera and Sargassum were growing together on the shallow grounds. When the patches of vegetations were thin, the young were found equally among both Zostera and Sargassum and the population density for these areas was approximately 0.5 to 1 per square metre in Naka-no-umi. On the contrary, when the patches were thick, the majority of young Sebastes inermis were found among Sargassum. A clump of Sargassum on an outcrop of rock covering an area of $2 \times 2 \mathrm{~m}^{2}$, for instance, was lodged by 11 youngs and none in the neighbouring Zostera growth. In an area near St. 400, where the thick growth of Zostera and Sargassum were lying side by side on the shallow bottom, a far more large number of youngs were found in the Sargassum belt and shoals of them cruising above Zostera directed to the Sargassum belt whenever they were threatened. Thus, although the data of observations are not statistically presented, it appears that the young black rockfish tends to reside in the Sargassum belt, though the importance is the presence of the submerged vegetations.

In the adjacent waters of the Seto Marine Biological Laboratory, young Sebastes inermis have been occasionally found in early summer months. In this region the adult population is very small and the Zostera belt developes poorly. Sargassum grows in enormous quantity on reefs and rocky shores in spring, but it nearly dies out usually by the middle of June and no suitable vegetations are available for the young. Eventually all the young were swimming alongside the rock cliffs.

The meaning of these habitats, to conclude, seems to be in that they firstly afford some sort of sheltering to the young which are still easily imperiled by 
enemies.

(3) The juvenile

During our survey of the Zostera and Sargassum belts the juvenile of Sebastes inermis, about 1 to $2 \mathrm{~cm}$ in body length, have seldom been collected with a beam trawl and a shank net, and it was also unsuccessful to collect them with the $1.5 \mathrm{~m}$ tow net in the Sargassum and Zostera belts. The sole specimen collected with the latter was from the bottom layer at St. 230 on February 22, 1959, and it measured $10.5 \mathrm{~mm}$ in body length.

However, the juvenile black rockfish was obtained in quantities from catches of the sand-lance filter nets. The season for this fishery commenced in early March and from its very beginning the juvenile of Sebastes inermis were caught. They were more abundant in the middle to late March and fewer relatively large individuals occurred in April. The distribution of body length of juvenile black

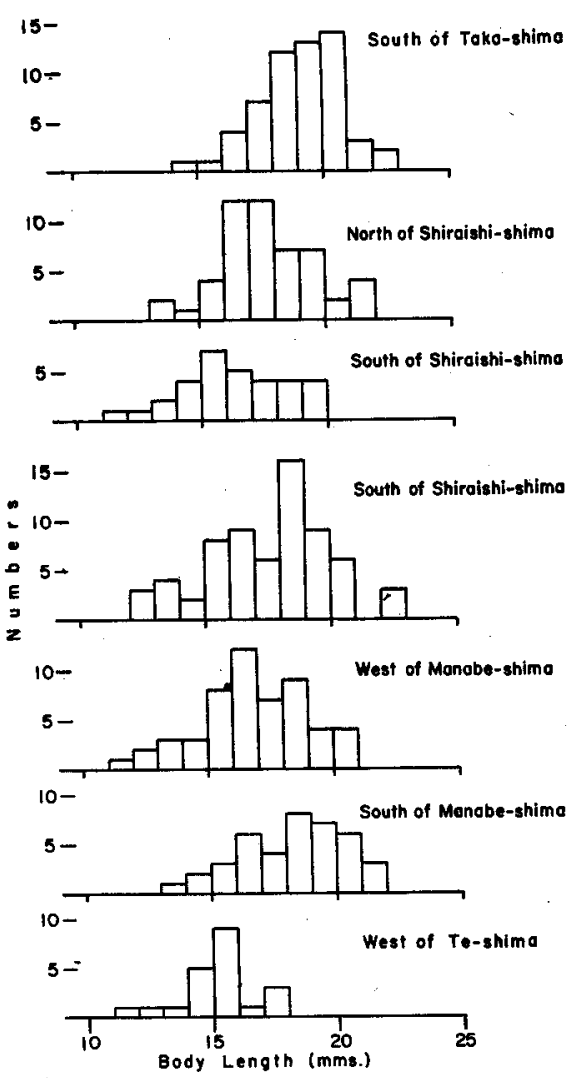

Fig. 9. Length-frequency distributions of catches of Sebastes inermis collected by the filter nets in various areas of the Kasaoka region in early March 1958.
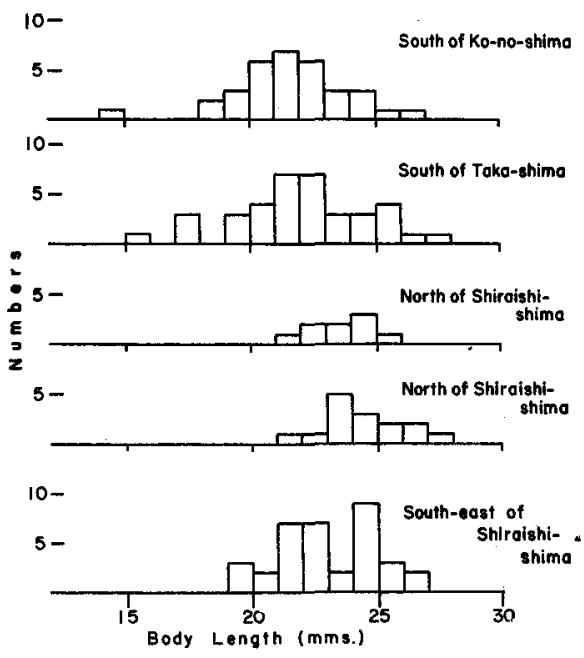

Fig. 10. Length-frequency distributions of catches of Sabastes inermis col. lected by the filter nets in various areas in the Kasaoka region in early April 1958. 


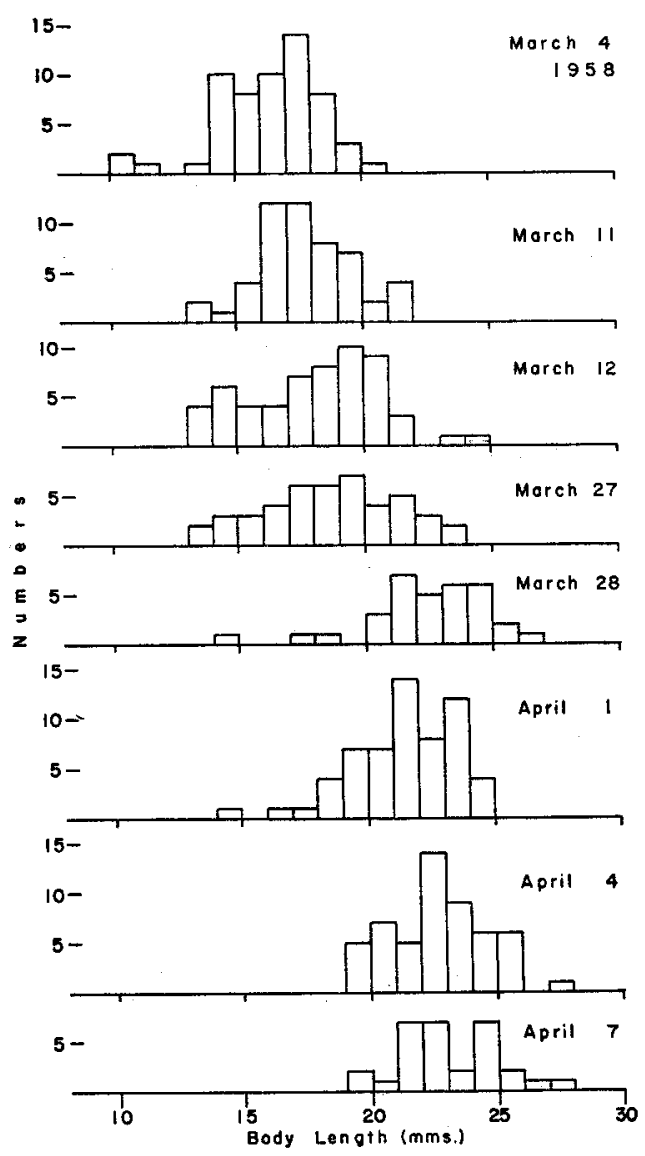

Fig. 11. Length-frequency distributions of Sebastes inermis collected by the filter nets in between Shiraishishima and Kitagi-shima in spring 1958.

rockfish collected by the filter nets are illustrated in Figs. 9-11. There are marked difference both as to the size distribution and amount of catches from area to area. The offshore and eastern populations comprised generally juveniles slightly larger than those of other areas. It appears, though it has to be proved, that these area to area difference are the results of the juvenile travelling inshore.

Since the sand-lance filter nets yielded very little catch of the juvenile of Sebastes inermis when the net failed to keep its position on the bottom and was lifted up by the current to the surface layer, the juvenile are possibly migrating in the bottom layers. The sole collection of the juvenile in the bottom layer can be regarded as another suggestion to this. Although the species, the mode of life and the actual size are different, this trend is quite similar to the juvenile 
of the Atlantic species, Sebastes marinus. TEMPLEMAN (1959), referring also to the findings of other workers, states "Although the greatest amount of towing resulting in the capture of the larvae shown in Fig. 16 was by 2 -metre plankton nets, only one redfish larva of $26 \mathrm{~mm}(37 \mathrm{~mm})$ was captured pelagically in a plankton net or young-fish trawl. Above this size all young redfish captures were by bottom otter trawl with a shrimp-net or stramin cover on the cod-end or by the Agassiz trawl dragged on the bottom." HENDERson (1961) also found that the redfish larvae over $25 \mathrm{~mm}$ in length were relatively scarce and none over $34 \mathrm{~mm}$ in the $10 \mathrm{~m}$ level and quoted the similar results of other investigations.

In one of the poorest catches by the sand-lance filter nets fished for 2 hours at a strait in the Kasaoka region, the juvenile of Sebastes inermis numbered approximately 1,100 , that is nearly 1 in $300 \mathrm{~m}^{3}$ of water, and in most instances in the mid-fishery season the catches of the juvenile were calculated to be well over than 2,000 times of the poorest. At the Sakai Channel the population desity of juvenile Sebastes inermis was estimated from the results of catches by a filter net to be approximately 0.03 to 0.3 in a cubic metre of water. These values are far more larger than that of 1 in $500 \mathrm{~m}^{3}$ recorded by the $1.5 \mathrm{~m}$ tow net at St. 230 in the open part of the sea. Presumably the juvenile are not distributing evenly over the waters in these high densities, but are aggregating to the bottom layers on straits in patches of varying size and density.

With these filter nets, the juvenile of Sebastes oblongus and Sebastes sp. (presumably Sebastes longispinis) were also caught. The juvenile of Sebastes oblongus were particularly numerous in the Naka-no-umi region in early March. Young Hexagrammos otakii and Agrammus agrammus and the leptochephalus larvae of Congridae were occasionally caught in fair numbers. At the Sakai Channel, the fishes and shrimps migrating pelagically were also more or less fished by the filter nets.

\section{(4) The larvae}

The larvae, smaller than $1 \mathrm{~cm}$ in body length, were taken entirely by the $0.5 \mathrm{~m}$ tow net. Since Sebastes inermis is a viviparous fish, the pelagic larvae caught comprises only a few forms. As it was impossible to occupy the whole region evenly, it was preferred to concentrate the regular collecting cruises more in the straits and coastal areas not far from the possible spawning grounds, and only at times the open part of the region was visited. Most of the larvae collected in the early months were those of the form just after emergination and the February specimens were all of the advanced form. The pelagic larvae of the scorpaenoid fishes have not been worked out extensively in Japan and rearing observations of the emerginated larvae have not been undertaken in the course of this investigation, their identification is not of supreme certainty. Further, the situation is worse, for, as has been stated by Mizue (1959b), although the breeding season is restricted to a rather short period of winter months for Sebastes 

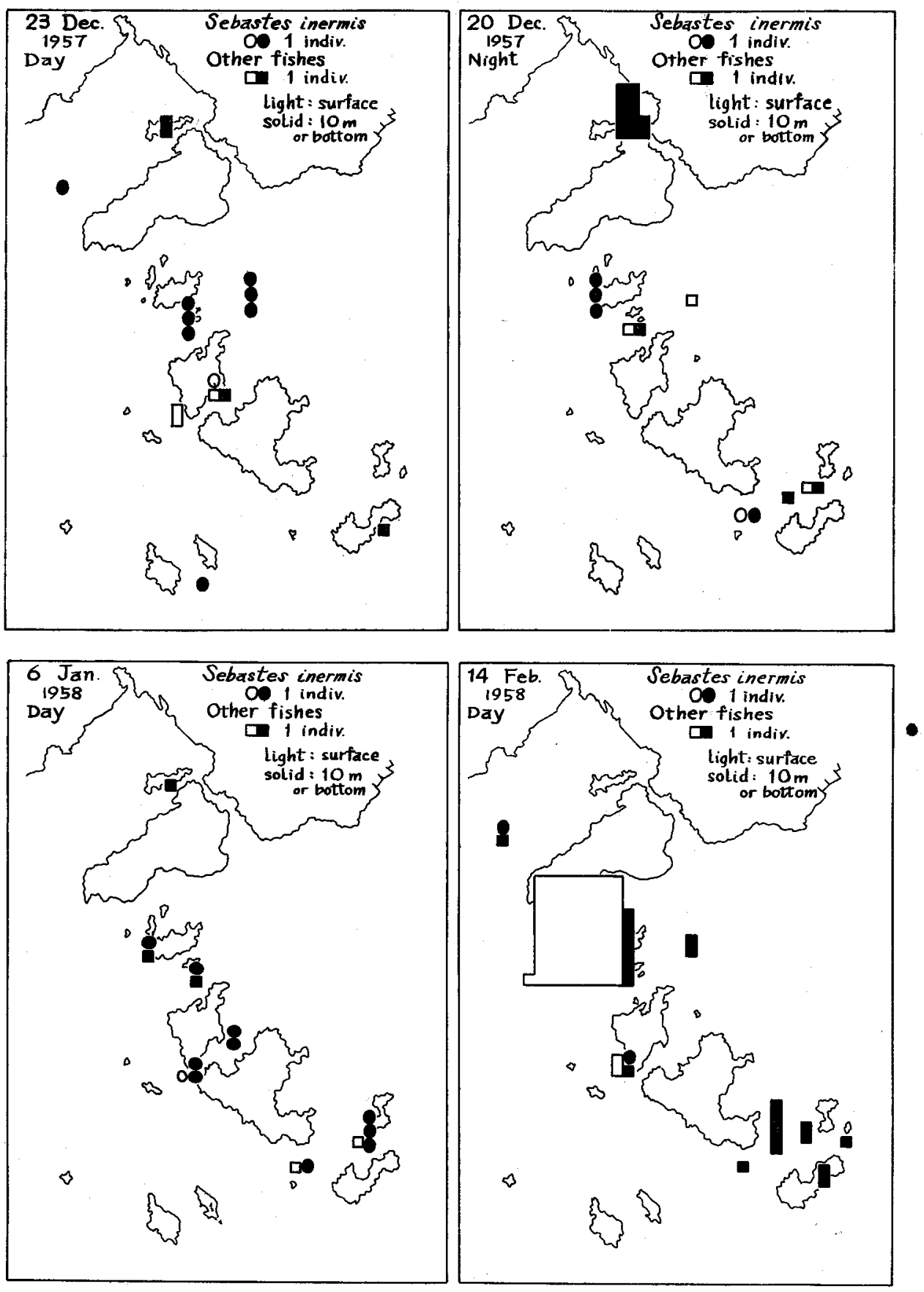

Fig. 12. Distribution and abundance of the larvae of Sebastes inermis and other fishes in the Kasaoka region. 
inermis, that of Sebastiscus marmoratus is extending far longer overlapping that of the former. The larvae of scorpaenoid fishes are closely resembling to each other in earlier stages, and, therefore, for identification of larvae from the hauls the general features and characteristics are followed down and up both from the adranced juvenile and pre-extrusion larvae. A relief is that Sebastes inermis holds overwhelming majority over the species of Sebastes in the region investigated.

A part of the results are illustrated in Fig. 12, and the data based on the materials collected by the Onomichi Branch of the Naikai Regional Fisheries Research Laboratory are also shown in Fig. 13. The main concentration of the

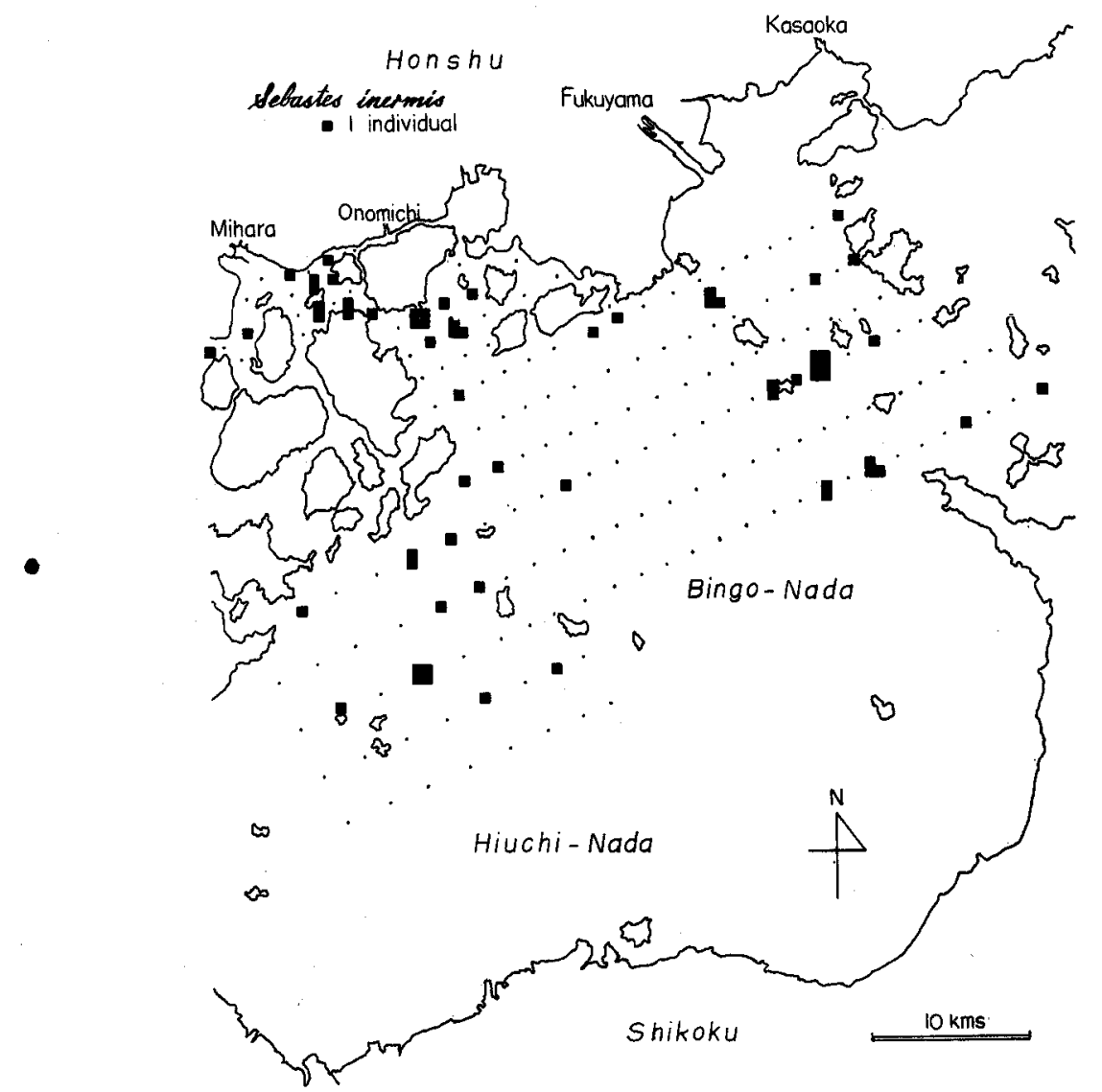

Fig. 13. Distribution and abundance of the larvae of Sebastes inermis in the Bingo-nada. All larvae of slightly differing forms collected during January and February 1959 are combined. Numbers are those taken by a tow net with the mouth of $10 \mathrm{~cm}$ diameter hauld horizontally for 10 minutes at a depth of 5 metres.

larvae in the vicinities of shores is evident, though on December 20, 1957, the larvae were collected amid the Bingo-nada at the $10 \mathrm{~m}$ level, which might be possible through dispersion by water movements. Even in the rather oceanic waters in 
the North Atlantic, TEMPLEMAN (1959) reports "Young redfish apparently have a long pelagic life near the surface. It is thus surprising, in view of the possibility of distribution far and wide by currents, that larval redfish at the surface follow so well the deeper contours." This characteristic feature of larval distribution is apparently the result of breeding habit of viviparous Sebastes.

The earliest occurrences of the pelagic larvae in the hauls were in late December. This first encounter shows some discrepancy from the hypothesis proposed by MizUe (1959b). He states that the maturation of ovaries starts in November and the larvae are extruded during from early January until early February. Mro (1960) reports the slightly earlier commencement of maturation of ovaries, and HATANAKA and IIzUKA $(1962 c)$ says that the larvae are first emerginated in the later quarter of December in the Matsushima Bay. During the present investigation the black rockfish with pre-extrusion larvae has been noticed at the Kasaoka Fishery Market in December (Fig. 19). These differences may be due to difference of locality.

There were no marked difference between the day and the night catches of the larvae, whereas they were more abundant in the mid-water layers than on the surface both in daytime and in night. The day and night migration of fish larvae are generally recognized, and recently BRIDGER (1956) has analyzed the day and night variation in catches of fish larvae and has found far more better yield by night. But this is not the case with Sebastes inermis larvae. STEele (1957) and Templeman (1959) have found the occurrence of palagic larvae of Sebastes marinus near the surface in the North Atlantic. As the mid-water layers in the present case are referred to distinguish it from the very surface, they are actually not much different from that indicated as near the surface by them.

The peak of the abundance of the larvae was attained in January. Although the data available are few, it seems that the distribution of Sebastes inermis larvae is not at all related to those of other fish larvae, mostly Ammodytes personatus GIRARD, nor to hydrographic factors such as the temperature, chlorinity, etc.

The distributions of macroplankton in the Kasaoka region during the winter months of 1957 to 1958 are also shown in Figs. 14-17. The plankton increased in amount considerably in February and was as well abundant during spring. This trend was generally observed in other years. The major contributions to this marked increase were almost entirely from the restricted members of plankton, namely Sagitta crassa naikaiensis ToKIOKA, Noctiluca scintillans MACARTNEY, Coscinodiscus spp. and some copepods, differing in composition from area to area and characterizing water masses. The distribution of Sagitta crassa naikaiensis was clearly concentrated to a particular area of the region, which caused high value of volume of plankton in the area. The pattern of distribution of Calanus finmarchicus (GUNNER) resembled that of Sagitta crassa naikaiensis. Not a few 

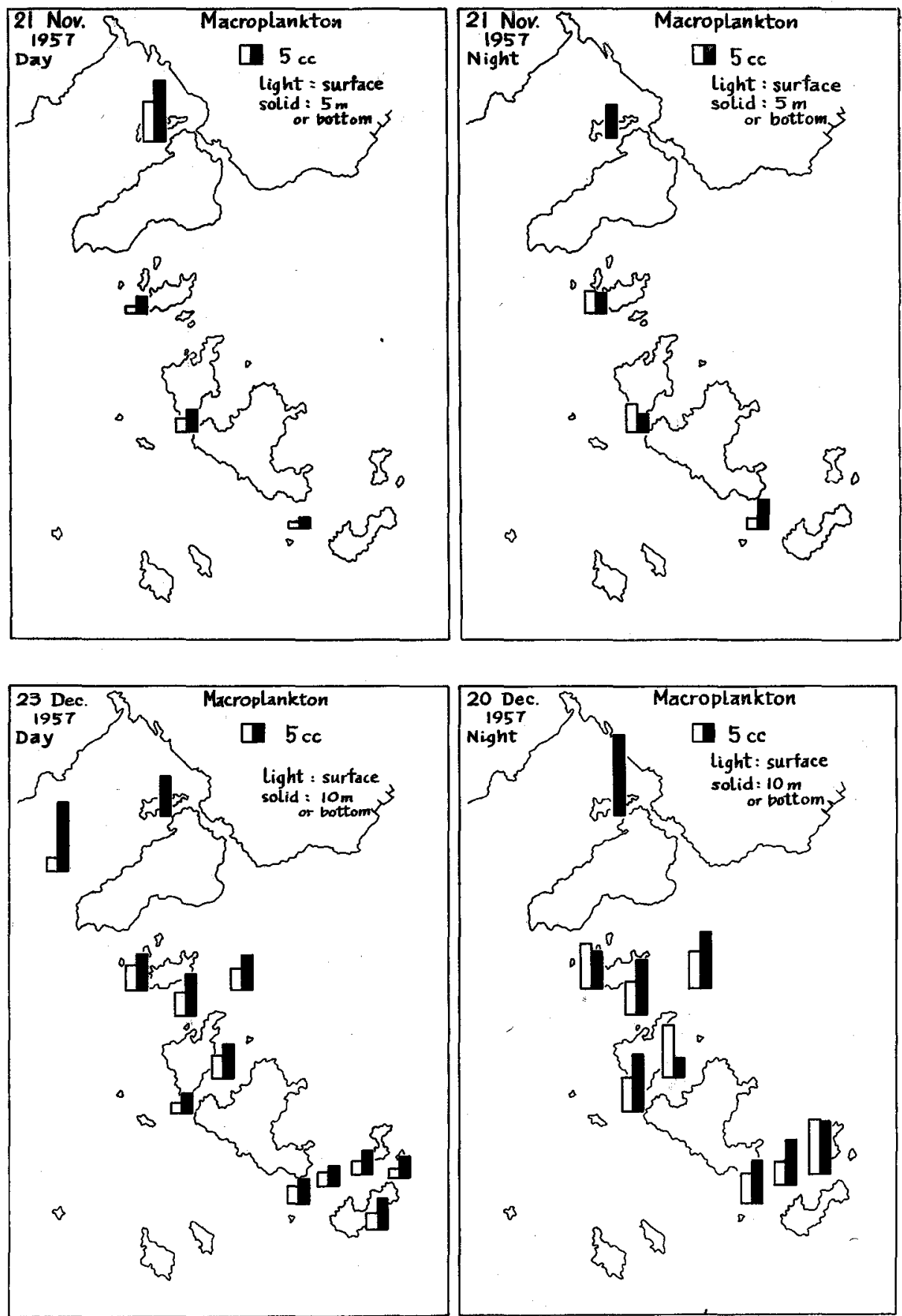

Fig. 14. Charts showing the distribution of total plankton in volume. 

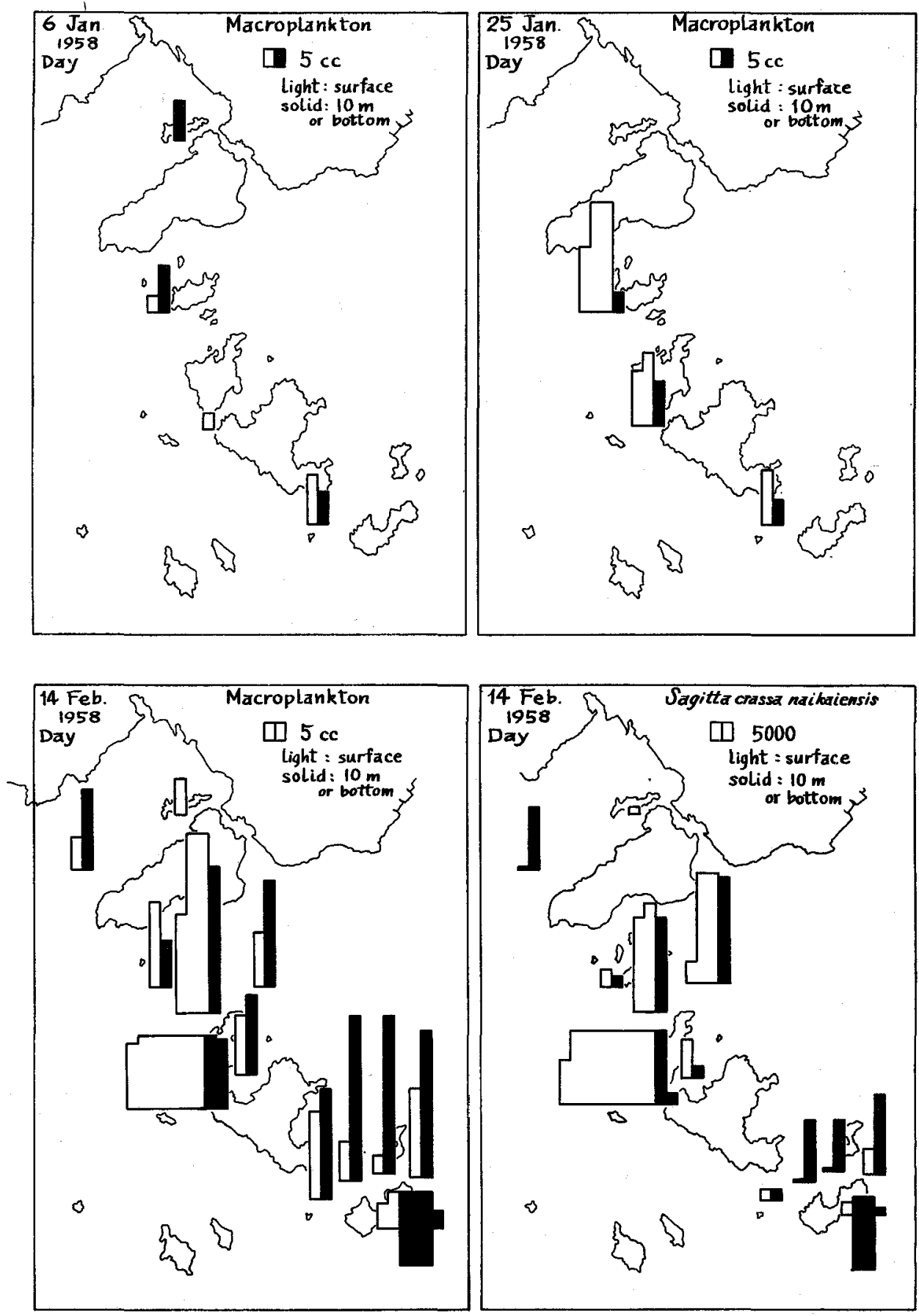

Fig. 15. Charts showing the distribution of total plankton in volume and Sagitta crassa naikaiensis. 

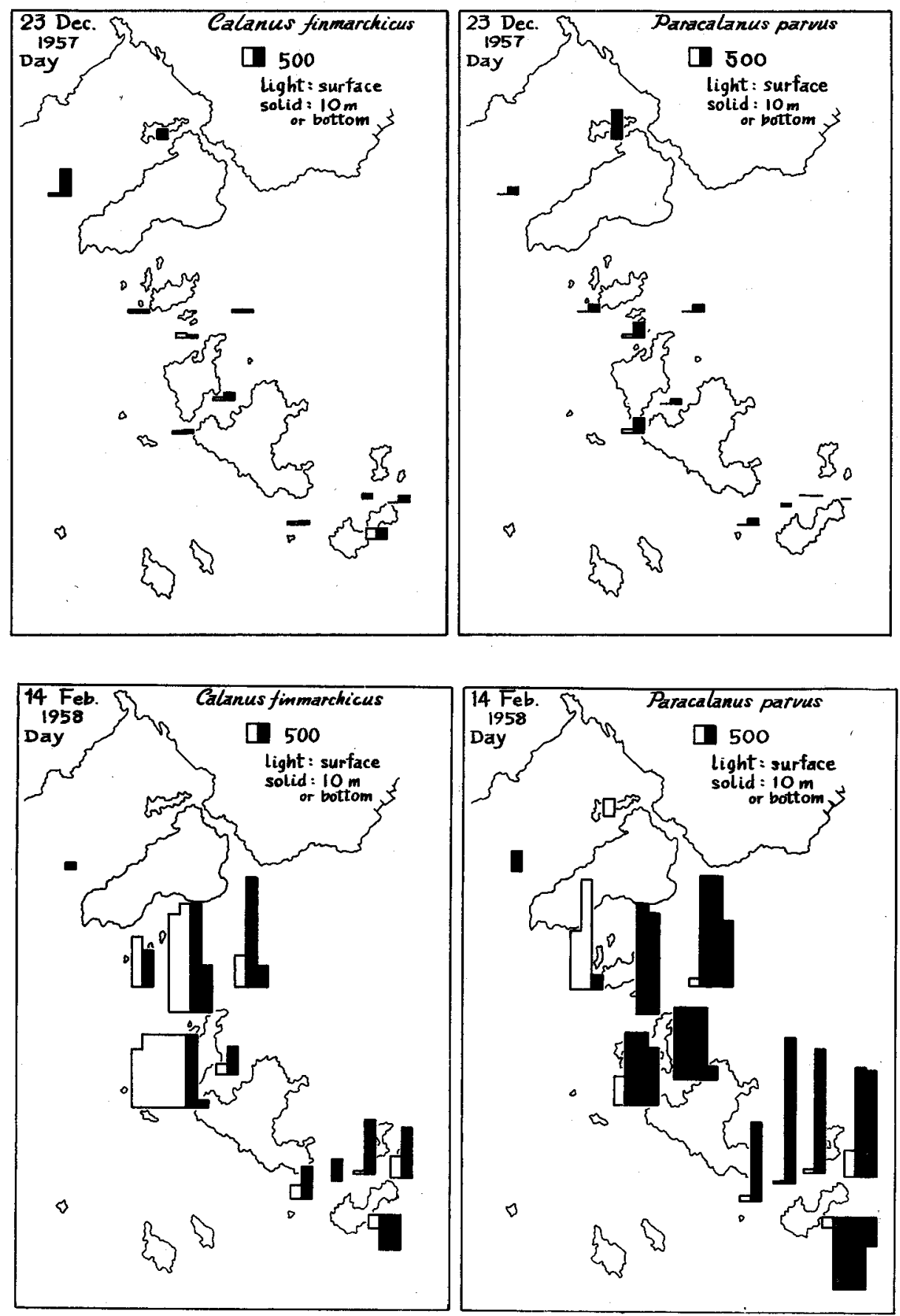

Fig. 16. Charts showing the distribution of Calanus finmarchicus and Paracalanus parvus. 

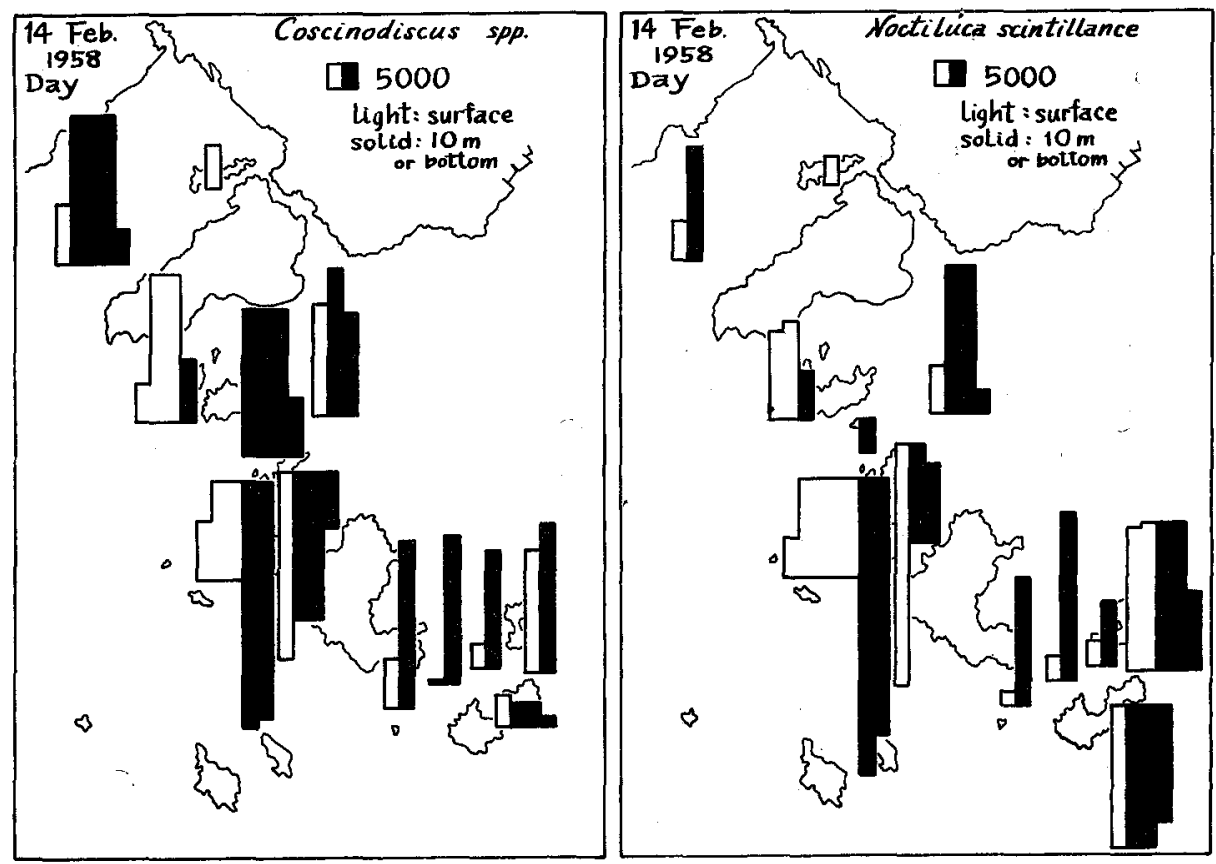

Fig. 17. Charts showing the distribution of Coscinodiscus spp. and Noctiluca scintillans.

Sagitta crassa naikaiensis were noticed to have eaten up Calanus finmarchicus and since the former is known to be voracious, there might be the predator-prey relationship between them, which could be the reason of the coincidence of distributions of these two animals. Among the bulk of Sagitta crassa naikaiensis taken on the surface at St. 200 on February 14, 1958, two animals were found swallowed up a fish larva each, probably the fry larvae of the sand-lance, and this figure equalled to that of the fish larvae found in the haul. Coscinodiscus spp. as a group had rather inshore distribution, whereas Noctiluca scintillans extended its range of distribution offshore. Paracalanus parvus was more abundant in the mid-water layers. As is seen, Calanus finmarchicus and Paracalanus parvus were not abundant in early winter, when there were a variety of copepods such as Acartia spinicauda Giesbrecht, Calanopia thompsoni Scott, Centropages furcatus (DANA), Labidocera bipinnata TANAKA, Tortanus forcipatus (GIESBRecht), Phyllopus sp., and Corycaeus spp. The patches of Corophium uenoi STEPHEnSEn were recorded in shallow waters and the considerable amounts of Actinotrocha and Ophioplutes larvae occurred at places. To conclude, the plankton tends to be less various in its composition as its total volume increases in spring, and there appears to be little or no relationship between the distributions of fish larvae and other planton organisms. This type of distribution of fish larvae should be especially characteristic to the larvae of Sebastes inermis and such that extrude the advanced 
progenies in the area where the spawning adults are inhabiting.

EINARSSON (1960) states “...temperature condition did not explain the great annual and regional variations in the abundance and distribution of the Sebastes fry," and shows that the fry of Sebastes marinus are confined to the oceanic zooplankton community characterized by an abundance of Calanus finmarchicus and the constant presence of larvae of Thysanoessa longicaudata. This kind of distributions or community are apparently considered on a larger geographical scale, and his result on the agreement in distribution of Sebastes fry and other zooplankton organisms is not relevant directly to the present case. TEMPLEMAN (1959) concludes, referring to TANING's view, "Larval redfish tend to be more numerous above the deeper water bank and channel contours where adult redfish are abundant."

Considering these results in relation to the hydrology and water movements of the Kasaoka region, the pattern of distribution of the pelagic larvae of black rockfish are ascribable to dispersion than to directional drift.

\section{(5) Related species}

Sebastes oblongus, the next abundant species of the genus Sebastes in both the Kasaoka and Naka-no-umi regions, inhabits in the more or less similar habitats. As has been referred to in the earlier discussions, the adult occur in the inshore Zostera belt commonly as well as in the Sargassum belt offshore. The young visit the Zostera belt earlier than those of Sebastes inermis. In the Naka-no-umi region the juvenile were caught fairly numerously by the filter net. In the juvenile and young stages the way of living of Sebastes oblongus appears to be similar to that of Sebastes inermis.

\section{Growth}

The growth of Sebastes inermis has been observed by Mio (1960) and HatanakA and IrzuKa (1962c), and they have presented the equations for the length-weight and other relations independently, some of which for the same relation are slightly differing between them. They also have determined the age of maturity from scales and otolithes as the end of third year of life, namely the age-group 2, at about $16 \mathrm{~cm}$ in body length. Differing from their conclusion, a few matured females, i.e. females in spawing condition, of about $11 \mathrm{~cm}$ were found in the Kasaoka region in January, which were supposed to be in the agegroup 1.

Evidence of the results of collection of larvae and examination of females at the fishery markets in the Kasaoka region indicates that the spawning season extends from late December to late January, which has been mentioned in the previous sections (Figs. 12 and 19). The data of examination of maturity of black rockfish caught by trammels in the Tomioka region during 1956 to 1959 revealed 
Table 4. Percentages of different stages of maturity of gonads in samples collected from the Tomioka area, Amakusa, during 1956 to 1959.

\begin{tabular}{|c|c|c|c|c|}
\hline Month & $\begin{array}{l}\text { Immature } \\
\text { Animals }\end{array}$ & $\begin{array}{l}\text { Mature } \\
\text { Animals }\end{array}$ & $\begin{array}{c}\text { With Mature Gonade } \\
\text { to Total } \\
\text { Mature Animals }\end{array}$ & $\begin{array}{c}\text { After Spawning } \\
\text { to Total } \\
\text { Mature Animals }\end{array}$ \\
\hline \multicolumn{5}{|l|}{ Females : } \\
\hline January & 29.4 & 70.6 & 41.6 & 8.3 \\
\hline February & 33.3 & 66.7 & 20.0 & 60.0 \\
\hline March & 64.3 & 35.7 & 0.0 & 100.0 \\
\hline April & 83.3 & 16.7 & 0.0 & 100.0 \\
\hline May & 100.0 & 0.0 & - & - \\
\hline June & 88.9 & 11.1 & 0.0 & 0.0 \\
\hline July & 100.0 & 0.0 & - & - \\
\hline August & 100.0 & 0.0 & - & - \\
\hline September & 100.0 & 0.0 & - & 一 \\
\hline October & 100.0 & 0.0 & - & - \\
\hline November & 80.0 & 20.0 & 0.0 & 0.0 \\
\hline December & 50.0 & 50.0 & 11.1 & 0.0 \\
\hline \multicolumn{5}{|l|}{ Males: } \\
\hline January & 50.0 & 50.0 & 50.0 & 0.0 \\
\hline February & 50.0 & 50.0 & 0.0 & 0.0 \\
\hline March & 55.5 & 44.5 & 75.0 & 0.0 \\
\hline April & 83.3 & 16.7 & 0.0 & 0.0 \\
\hline May & 100.0 & 0.0 & - & - \\
\hline June & 100.0 & 0.0 & - & - \\
\hline July & 87.5 & 12.5 & 100.0 & 0.0 \\
\hline August & 100.0 & 0.0 & - & - \\
\hline September & - & - & - & - \\
\hline October & 100.0 & 0.0 & - & - \\
\hline November & 70.0 & 30.0 & 0.0 & 0.0 \\
\hline December & 40.0 & 60.0 & 33.3 & 66.7 \\
\hline
\end{tabular}

similarly that the spawning season was extending from December to February (Table 4).

Basing on specimens collected during the survey in the Naka-no-umi region, the logalithms of body weights are plotted against the logalithms of body lengths in Fig. 18: As has been stated by Thompson (1942) that "inasmuch as the animal is continually apt to change its body proportions during life, $k$ also is continually subject to change," the condition coefficient $k$ in the length-weight equation is an good index of any transformation of an animal. As is seen from Fig. 18, two regressions are applicable for the data, one for those between 2 and $20 \mathrm{~cm}$ in body length and the other for those above $20 \mathrm{~cm}$. It is easily supposed that the third regression may be applied for the data of those smaller than $2 \mathrm{~cm}$. The 


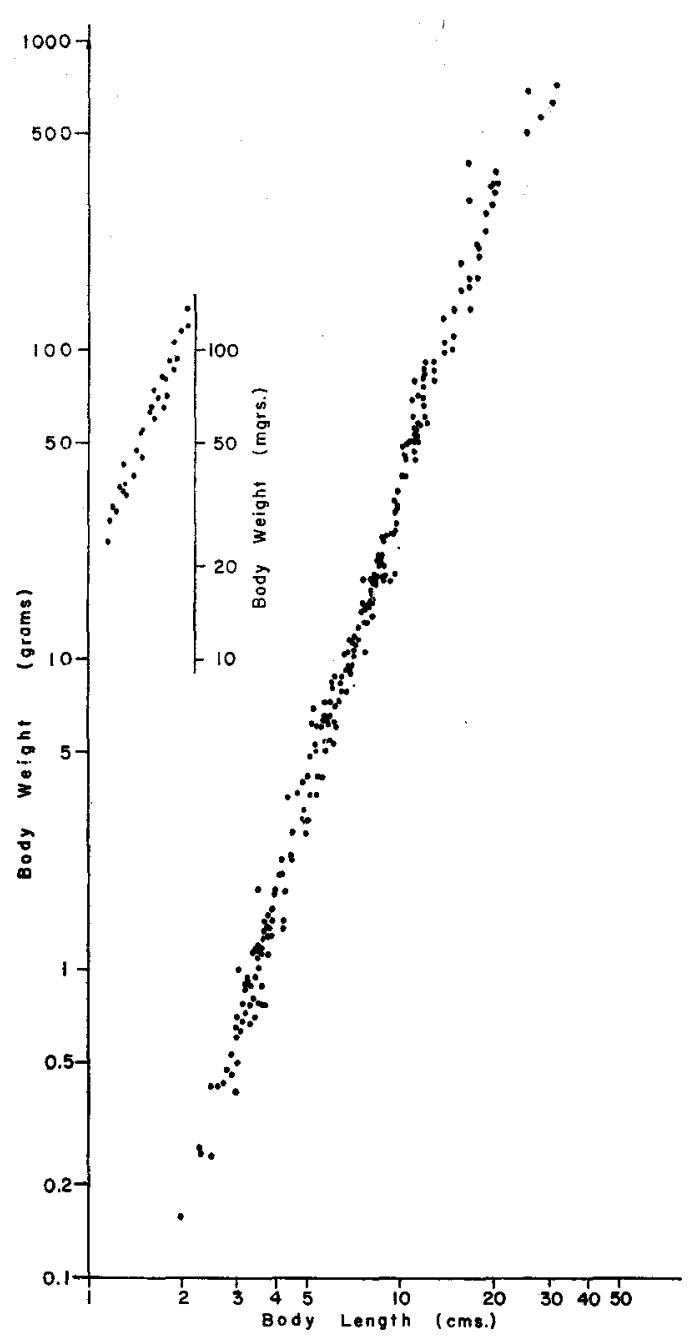

Fig. 18. Relation between length and weight in Sebastes inermis of the Naka-no-umi region.

similar finding has also been reported by Schamardina (1960). He has also analysed the relations between various characters and found different types of sets of regressions.

The larvae, emerginated from the female parents, measured around $4.5 \mathrm{~mm}$ in total length and in February the largest pelagic larva collected by the tow net attained to $7.4 \mathrm{~mm}$ in body length. The migrating juvenile, caught in March and April by the filter nets, were largely 1 to $3 \mathrm{~cm}$ and they grew up to 5 to $6 \mathrm{~cm}$ in June. In December, nearly 1 year after emergination, the average size of 
black rockfish was $8 \mathrm{~cm}$ in body length. Monthly length-frequency distributions, based on the samples collected in the Kasaoka and Naka-no-umi regions are shown in Fig. 19, and similar illustrations are presented for the materials caught in the Zostera and the Sargassum belt in the Tomioka region separately in Figs. 20-21.

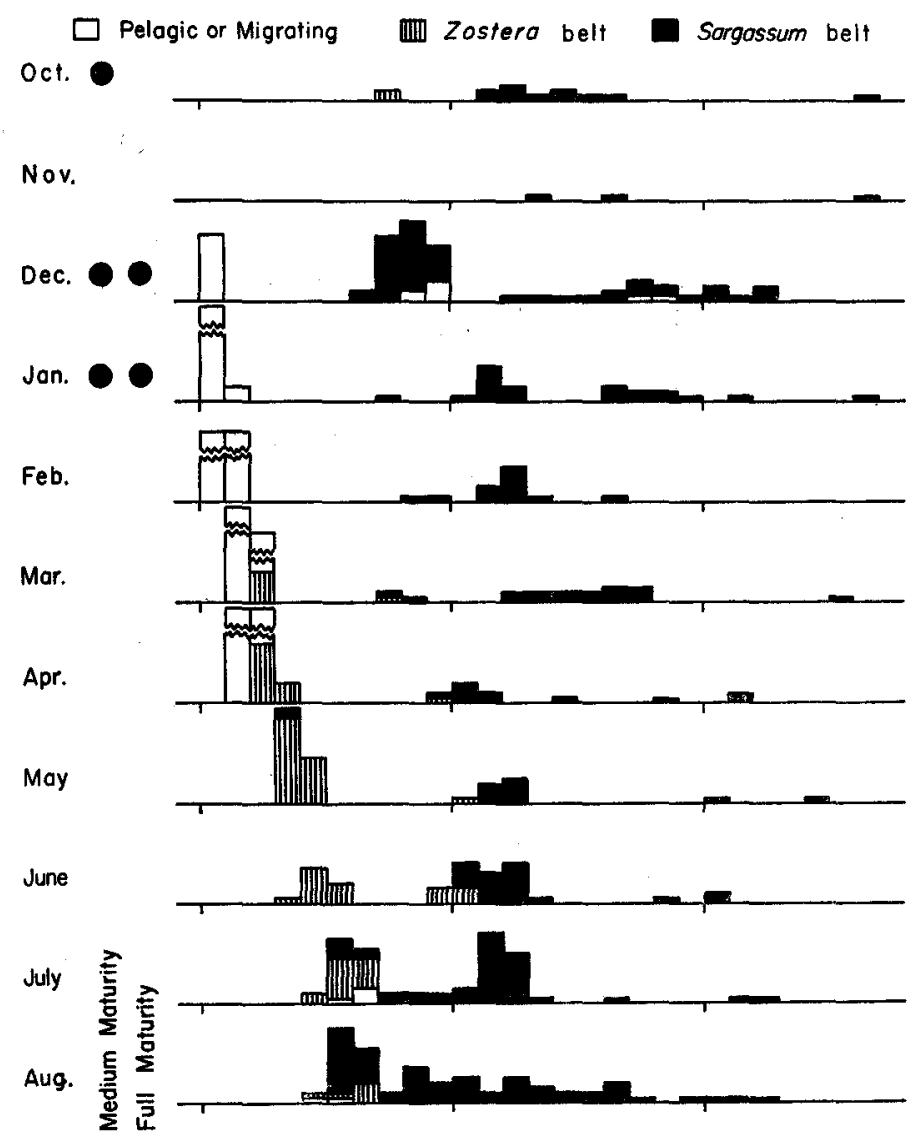

Sept.

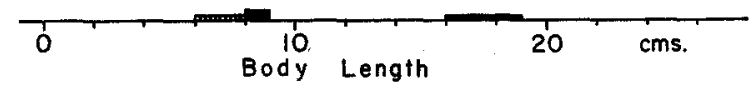

Fig. 19. Monthly length-frequency distributions of Sebastes inermis collected both in the Kasaoka and Naka-no-umi regions during 1954 to 1959 . 


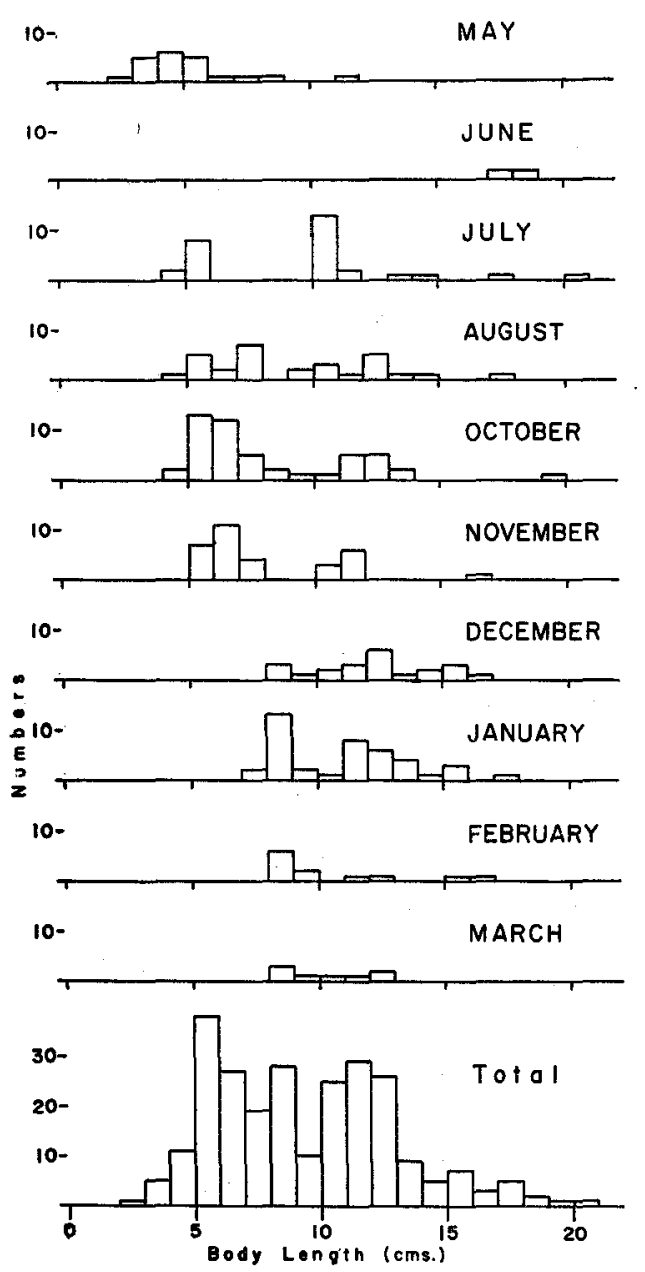

Fig. 20. Monthly length-frequency distributions of Sebastes inermis collected in the Zostera belts in the Tomioka region. 


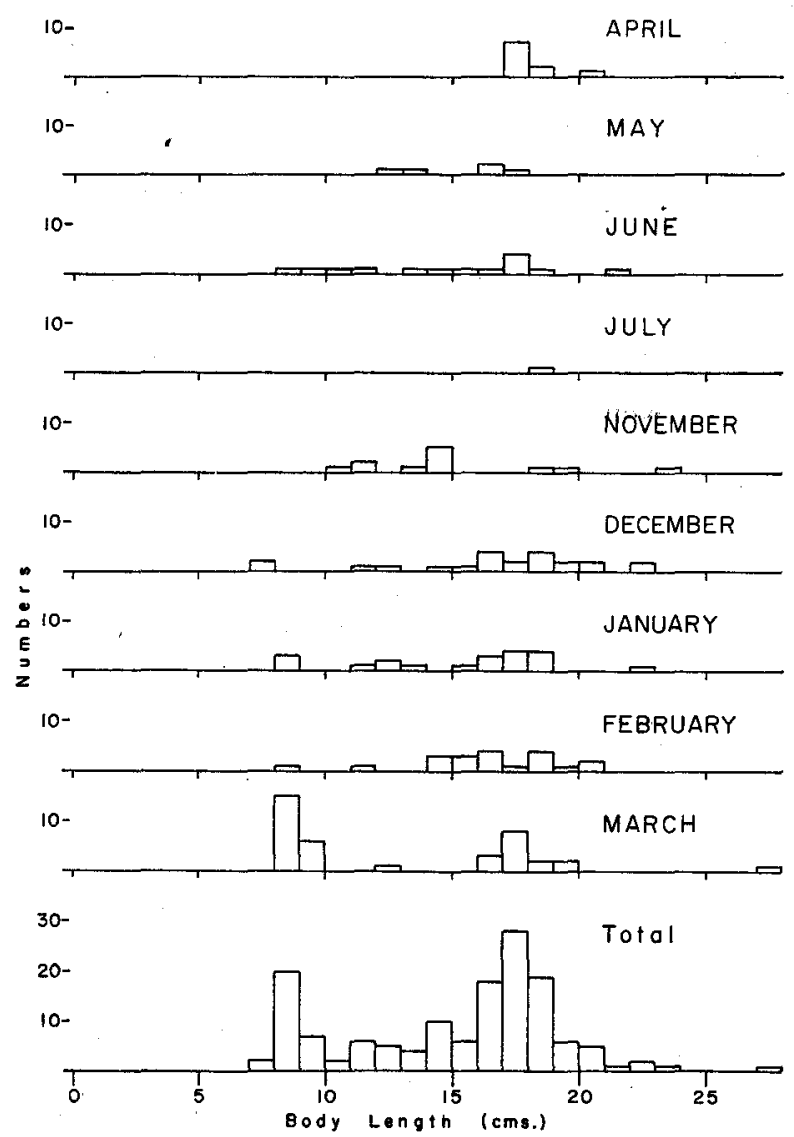

Fig. 21. Monthly length-frequency distributions of Sebastes inermis collected in the Sargassum belts in the Tomioka region.

The general progression of size distributions of Sebastes oblongus is similar to that of Sebastes inermis (Fig. 22). The rate of growth appears slightly higher than that of the latter, as has been reported by HatanakA and IizukA (1962c).

\section{Morphology}

In the preceding section, the growth of Sebastes inermis has been treated particularly from the point of view of size increase, and in this section the morphological changes are briefly described. A short description on the larvae and juvenile of Sebastes inermis has been given by UCHIDA (1943) and the primary object of the present paper is not to afford further detailed descriptions of them. Since the development or morphological changes are closely correlated with 


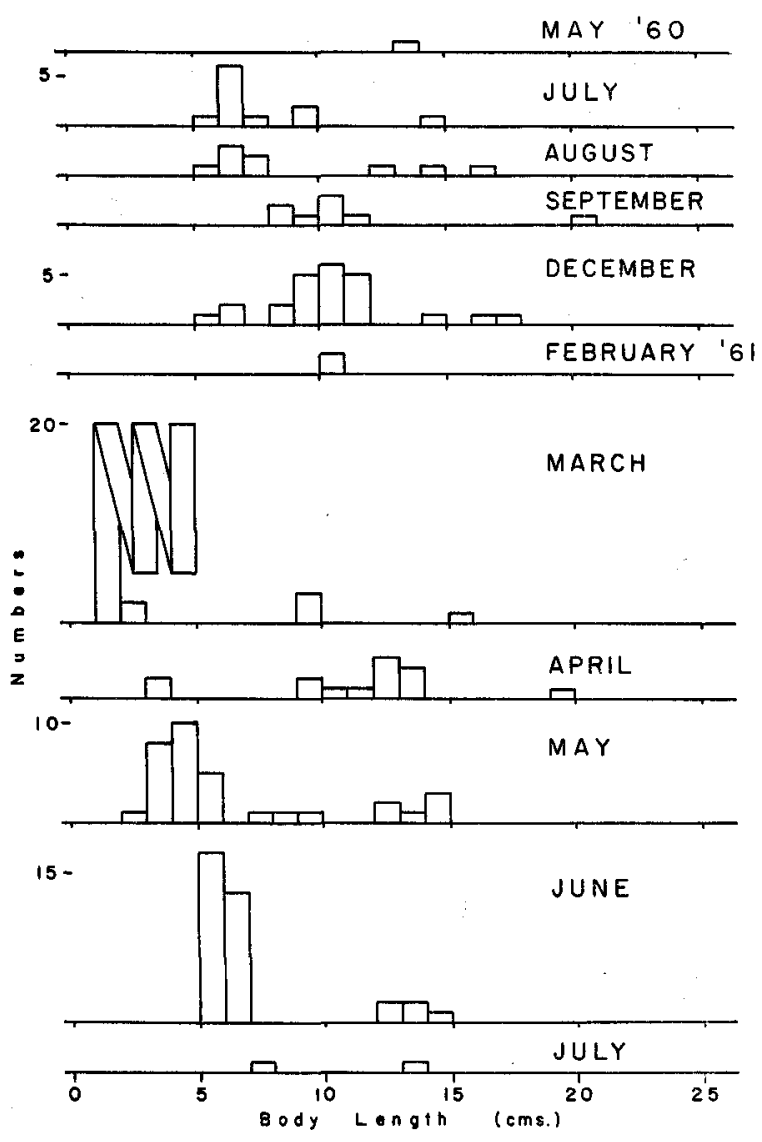

Fig. 22. Monthly length-frequency distributions of Sebastes oblongus collected in the Naka-no-umi region.

ecology, they are certainly less suggestive if dealt with separately. These will be discussed again together with the community aspects in the last section.

All observations were made on the specimens preserved in $70 \%$ alcohol.

(1) The yolk-sac (pre-extrusion) larva (Fig. 23, A-B)

The specimens were taken out from the matured female gonad. This form may not occur in nature as pelagic larvae.

The larvae measure 4 to $4.7 \mathrm{~mm}$ in total length. The yolk material has not been absorbed completely. The body is slender. All fins except the pectoral are not differentiated. No spines can be seen on the head and operculum. There, too, are no pigmentation in the head region and along the posterior portion of trunk. Gill rakers are not developed. The numbers of the myomeres anterior and posterior to the anus are 7 and 17 respectively. The snout is short and round. The hypural bones are not developed. 
(2) The pelagic early fry larva (Fig. 23, C)

The larvae, 4 to $5 \mathrm{~mm}$ in total length, have almost absorbed the yolk material, but fins are not yet differentiated. The body is still slender, but the snout is slightly produced. Parietal spines and preopercular spines are not developing. One melanophore is present on the dorsal surface of brain case. The numbers of myomeres anterior and posterior to the anus are 7 and 17 respectively. Gill rakers are not developed.
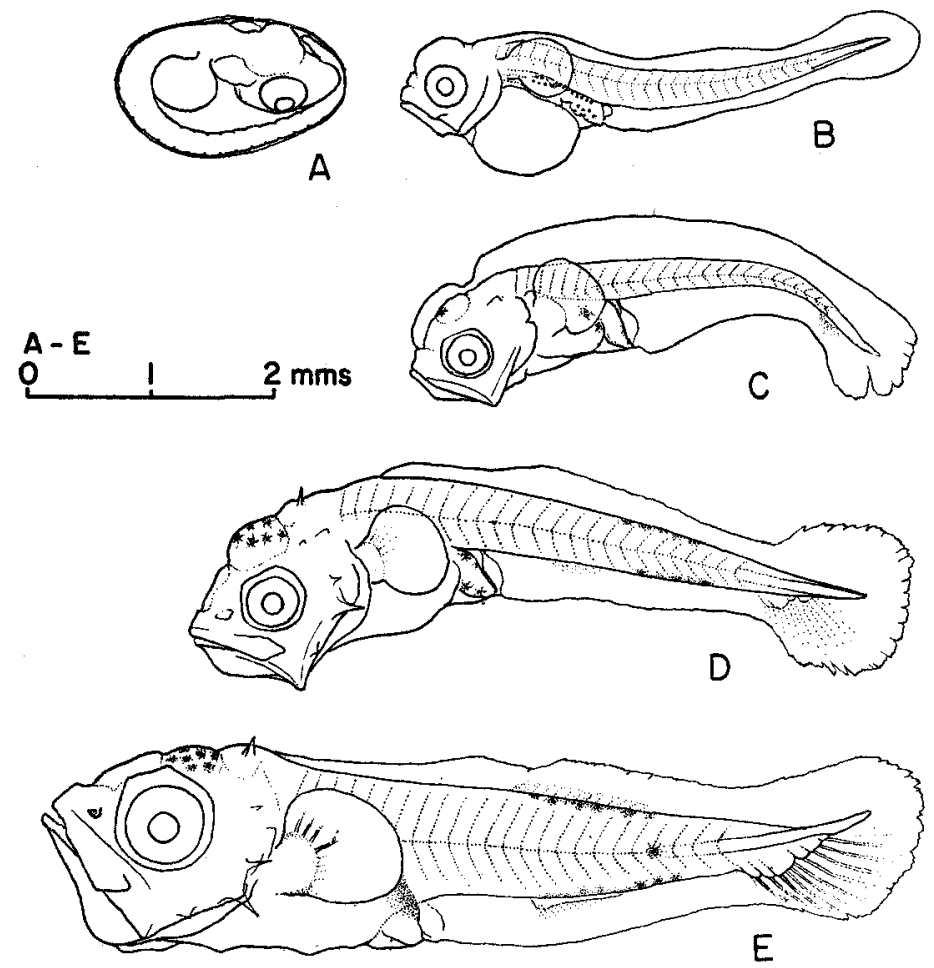

Fig. 23. Yolk-sac (pre-extrusion) larvae (A-B), pelagic early fry larva (C) pelagic late fry larvae (D-E) of Sebastes inermis.

(3) The pelagic late fry larva (Fig. 23, D-E)

The larvae of about 6 to $10 \mathrm{~mm}$ have rather deep, stumpy shape. Separation of the finfold into dorsal, caudal and anal portions is distinct. The urostyle has turned slightly upward and hypural bones are developing. Some fin rays are discernible in the pectoral and candal fins. Parietal and preopercular spines have appeared. The pigmentation has progressed and a cap of about 14 melanophores are present on the dorsal surface of brain case, and a row of arborescent melanophores on both dorsal and ventral sides of postanal trunk. The numbers of 
myomeres anterior and posterior to the anus are 7 and 17 respectively. The first gill arch has none to 4 gill rakers on the upper limb and 12 to 19 on the lower.

(4) The migrating juvenile (Fig. 24, A-C)

The juvenile are between 1 and $3 \mathrm{~cm}$ in body length and their body shape is deep, much more resembling the adult. Parietal and preopercular spines are strong, but the formers tend to be less conspicuous in larger juvenile. Additional pigmentation is seen at the base of dorsal and anal fins and is developing

A

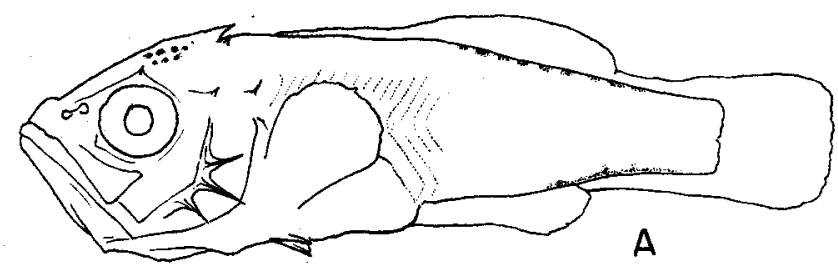

요다 $5 \mathrm{mms}$

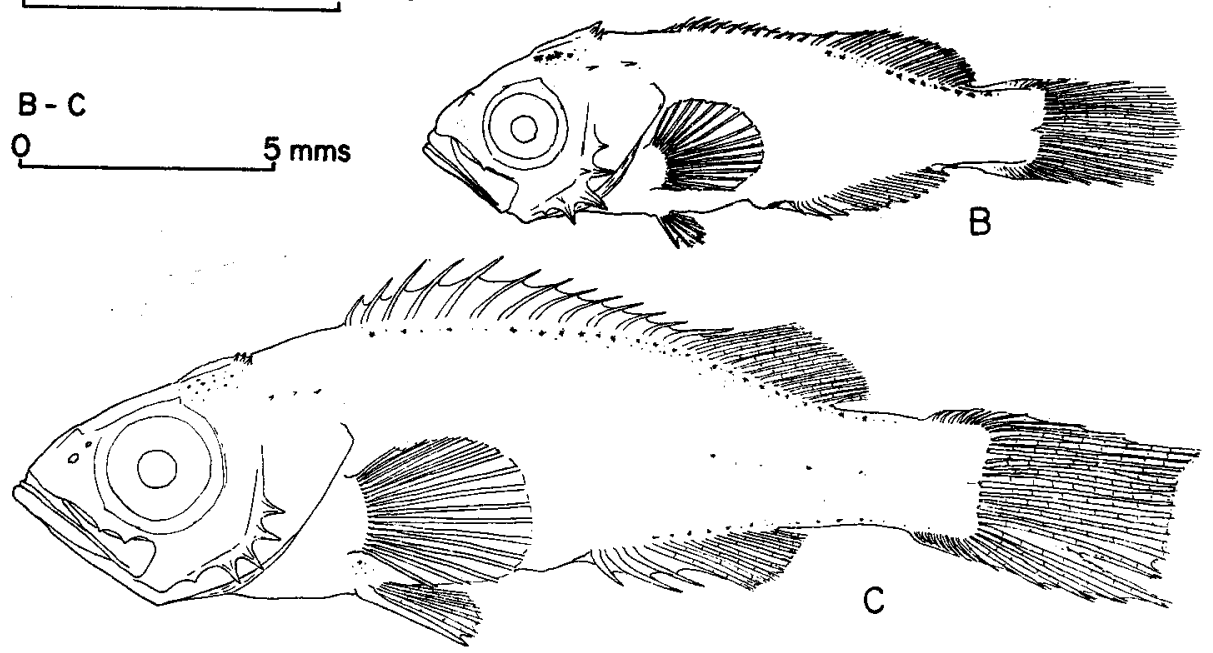

Fig. 24. Migrating juveniles (A-C) of Sebastes inermis.

on the body into distinct pattern. The juvenile have 4 to 10 gill rakers on the upper limb of the first arch and 19 to 25 on the lower, obtaining the full complement. There can be seen at least 17 myomeres in the postanal portion of trunk.

(5) The settling young (Fig. 25, A)

The fish ranging from $3 \mathrm{~cm}$ in body length up to $6 \mathrm{~cm}$ resemble the adult in general appearance. Its colouration is rather greenish brown and the pattern of pigmentation on the body is more pronounced. Parietal spines are nearly covered by the skin and inconspicuous. 


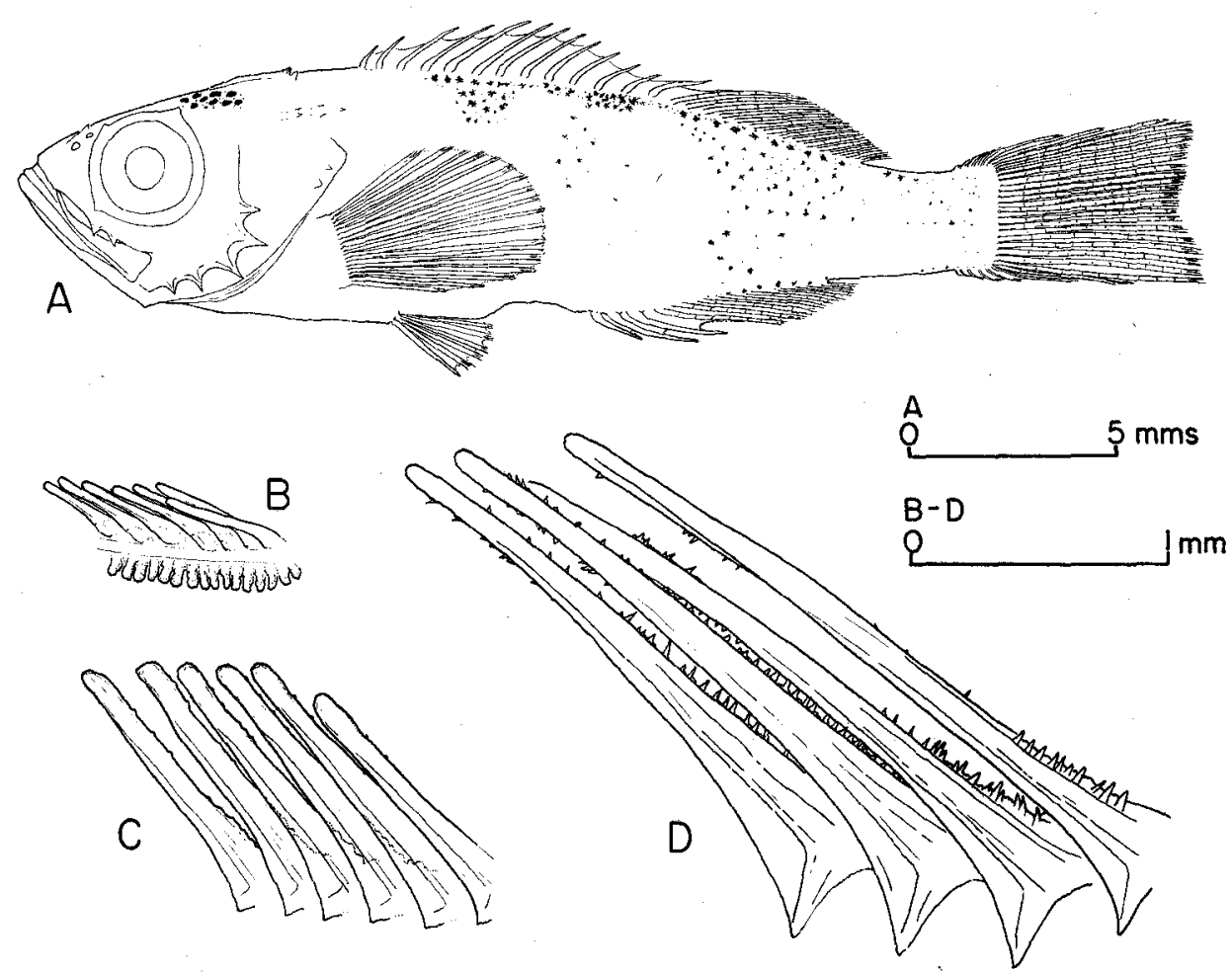

Fig. 25. Settling young (A) of Sebastes inermis; the posterior gill rakers on the lower limb of the juvenile (b.1. $11.3 \mathrm{~mm}$ ) (B), of the settling young (b.1. $26.8 \mathrm{~mm}$ ) (C) and of the migrating young (b.1. $53.0 \mathrm{~mm}$ ) (D).

\section{Food}

One of the most important ecological relationships among animals is the food relationship.

(1) The food of the pelagic fry larvae and migrating juvenile in relation to the plankton

The contents of stomachs of the pelagic fry larvae and migrating juvenile were entirely pelagic animals, mostly copepods both in number and in volume. The distribution and abundance of the plankton in winter in the Kasaoka region has been mentioned in the earlier section and here a part of the data of relative abundance of plankton species are summarized in Table 5 .

The early fry larvae taken in tow net hauls were few and most of them had no identifiable contents in their stomach, and, therefore, their examination failed to produce any statistical representation. One larva of about $4.5 \mathrm{~mm}$ only was found eaten food and the contents of its stomach were two eggs presumably 
Table 5. Percentage composition by number of major constituents of plankton in the Kasaoka region in March 1958.

\begin{tabular}{|c|c|c|c|c|c|c|c|}
\hline \multirow{2}{*}{ Species } & \multirow{2}{*}{ Date } & \multicolumn{4}{|c|}{ March 12} & \multicolumn{2}{|c|}{ March 16} \\
\hline & & 110 & 120 . & 200 & 210 & 102 & 210 \\
\hline \multicolumn{2}{|c|}{ Noctiluca scintillans MACARTNEY } & 54.5 & + & + & 2.1 & + & + \\
\hline \multicolumn{2}{|c|}{ Sagitta crassa naikaiensis ToKIOKA } & 2.0 & - & 7.4 & - & - & 一 \\
\hline \multicolumn{2}{|c|}{ Calanus finmarchicus (GUNNERUS) } & - & 4.8 & - & 10.4 & + & 6.1 \\
\hline \multicolumn{2}{|c|}{ Paracalanus parvus GIESBRECHT } & 9.1 & 36.5 & 7.4 & 20.8 & 35.7 & 40.8 \\
\hline \multicolumn{2}{|c|}{ Centropages abdominalis SATO } & 8.1 & - & 18.5 & 4.2 & 7.1 & + \\
\hline \multicolumn{2}{|c|}{ Acartia clausi GIESBRECHT } & 18.2 & 20.6 & 18.5 & 12.5 & 7.1 & 2.1 \\
\hline \multicolumn{2}{|c|}{ Oithona similis GIESBRECHT } & 7.1 & 7.9 & 18.5 & 4.2 & 33.3 & 32.7 \\
\hline \multicolumn{2}{|c|}{ Microsetella rosea (DANA) } & - & 15.9 & 7.4 & 27.1 & 14.3 & 6.1 \\
\hline \multicolumn{2}{|c|}{ Corycaeus spp. } & - & 4.8 & 7.4 & 16.7 & 2.4 & 12.3 \\
\hline \multicolumn{2}{|c|}{ Coscinodiscus spp. } & Ht & H & H & Ht & + & + \\
\hline \multicolumn{2}{|c|}{ Rhizosolenia spp. } & - & - & - & - & H & Ht \\
\hline \multicolumn{2}{|c|}{ Chaetoceros spp. } & 卅 & H & H & + & 卅 & + \\
\hline \multicolumn{2}{|l|}{ Eucampia spp. } & Ht & - & - & - & - & - \\
\hline \multicolumn{2}{|l|}{ Nitzschia spp. } & 井 & - & - & - & - & - \\
\hline \multicolumn{2}{|l|}{ Ceratium spp. } & H & H & m & 世 & + & - \\
\hline
\end{tabular}

Table 6. Relative imporiance of three principal food copepods of young Sebastes inermis, shown as percentages by number in its diet, in the Kasaoka region in spring 1957.

\begin{tabular}{|c|c|c|c|c|c|c|c|}
\hline \multirow{2}{*}{$\begin{array}{c}\text { Body } \\
\text { Length } \\
\text { (mms) }\end{array}$} & \multirow{2}{*}{ Copepods } & Date & $\begin{array}{c}\text { March } \\
4\end{array}$ & $\begin{array}{c}\text { March } \\
27\end{array}$ & $\begin{array}{c}\text { March } \\
28\end{array}$ & $\begin{array}{c}\text { April } \\
3\end{array}$ & $\begin{array}{c}\text { April } \\
3\end{array}$ \\
\hline & & Locality & $\begin{array}{c}\text { Shiraishi- } \\
\text { shima }\end{array}$ & $\begin{array}{c}\text { Shiraishi- } \\
\text { shima }\end{array}$ & Te-shima & $\begin{array}{c}\text { Shiraishi- } \\
\text { shima }\end{array}$ & Hi-shima \\
\hline \multirow{3}{*}{$\begin{array}{l}10 \\
\text { to } \\
16\end{array}$} & \multirow{3}{*}{\multicolumn{2}{|c|}{$\begin{array}{l}\text { Paracalanus parvus (CLAUS) } \\
\text { Acartia clausi GIESBRECHT } \\
\text { Centropages abdominalis SATO }\end{array}$}} & 88.9 & 44.4 & 42.9 & 35.3 & \\
\hline & & & 2.8 & 11.1 & 21.7 & 41.2 & \\
\hline & & & 0 & 44.4 & 23.9 & 17.6 & \\
\hline \multirow{3}{*}{$\begin{array}{l}16 \\
\text { to } \\
20\end{array}$} & \multirow{3}{*}{\multicolumn{2}{|c|}{$\begin{array}{l}\text { Paracalanus parvus (CLAUS) } \\
\text { Acartia clausi GIESBRECHT } \\
\text { Centropages abdominalis SATO }\end{array}$}} & 90.9 & 4.3 & 41.9 & 34.4 & 25.9 \\
\hline & & & 0 & 16.3 & 21.9 & 4.3 & 0 \\
\hline & & & 0 & 75.0 & 25.6 & 59.7 & 74.0 \\
\hline \multirow{3}{*}{$\begin{array}{l}20 \\
\text { to } \\
25\end{array}$} & \multirow{3}{*}{\multicolumn{2}{|c|}{$\begin{array}{l}\text { Paracalanus parvus (CLAUS) } \\
\text { Acartia clausi GIESBRECHT } \\
\text { Centropages abdominalis SATO }\end{array}$}} & & 6.4 & 32.5 & 26.8 & 20.7 \\
\hline & & & & 4.0 & 23.3 & 26.8 & 17.2 \\
\hline & & & & 84.0 & 32.9 & 44.6 & 58.6 \\
\hline
\end{tabular}

of copepods. This observation agrees with the finding of EINARsson (1960) who gave copepod egg as a principal food item of smaller fry of Sebastes marinus.

Very few late fry larvae were available for examination of contents of stomachs. The diet of late fry larvae collected in February was exclusively Paracalanus parvus, one or two for each larva.

It is somewhat surprising that the larvae in such an early stage and of smaller size eat agile copepods of fair size compared to the larvae themselves 
Table 7. Relative importance of four principal food copepods of juvenile Sebastes inermis, shown as percentages by number, percentage occurrence and average numbers in its diet, in the Kasaoka region in spring 1958.

\begin{tabular}{|c|c|c|c|c|c|c|c|c|}
\hline \multirow{2}{*}{$\begin{array}{c}\text { Date } \\
\text { and } \\
\text { Locality }\end{array}$} & \multirow{2}{*}{$\begin{array}{l}\text { Body } \\
\text { Length } \\
\text { (mms) }\end{array}$} & \multirow[b]{2}{*}{ Copepods } & \multicolumn{3}{|c|}{ Early Morning } & \multicolumn{3}{|c|}{ Afternoon } \\
\hline & & & $\begin{array}{c}\text { Percentage } \\
\text { of Total } \\
\text { Number }\end{array}$ & $\begin{array}{l}\text { Percentage } \\
\text { Occurrence }\end{array}$ & $\begin{array}{l}\text { Average } \\
\text { Number per } \\
\text { Stomach }\end{array}$ & $\begin{array}{c}\text { Percentage } \\
\text { of Total } \\
\text { Number }\end{array}$ & $\begin{array}{l}\text { Percentage } \\
\text { Occurrence }\end{array}$ & $\begin{array}{l}\text { Average } \\
\text { Number per } \\
\text { Stomach }\end{array}$ \\
\hline \multirow{4}{*}{$\begin{array}{c}\text { March } \\
11 \\
\text { St. } 120\end{array}$} & \multirow{4}{*}{$\begin{array}{l}16 \\
\text { to } \\
20\end{array}$} & Paracalanus parvus & 74.0 & 100.0 & 2.5 & 59.4 & 100.0 & 6.8 \\
\hline & & Acartia clausi & 0 & 0 & 0 & 4.3 & 33.3 & 0.5 \\
\hline & & Centropages abdominalis & 0 & 0 & 0 & 10.1 & 66.7 & 1.1 \\
\hline & & Calanus finmarchicus & 25.9 & 66.7 & 0.8 & 26.1 & 100.0 & 3.0 \\
\hline \multirow{8}{*}{$\begin{array}{c}\text { March } \\
\quad 28 \\
\text { St. } 210\end{array}$} & \multirow{4}{*}{$\begin{array}{l}16 \\
\text { to } \\
20\end{array}$} & Paracalanus parvus & 31.7 & 47.0 & 3.0 & & & \\
\hline & & Acartia clausi & 35.2 & 70.5 & 3.3 & 1 & & \\
\hline & & Centropages abdominalis & 27.0 & 76.5 & 2.5 & & & \\
\hline & & Calanus finmarchicus & 3.5 & 33.0 & 0.3 & & & \\
\hline & \multirow{4}{*}{$\begin{array}{l}20 \\
\text { to } \\
25\end{array}$} & Paracalanus parvus & 3.1 & 14.3 & 0.2 & 4.2 & 50.0 & 1.5 \\
\hline & & Acartia clausi & 31.2 & 42.8 & 1.4 & 4.2 & 50.0 & 1.5 \\
\hline & & Centropages abdominalis & 65.6 & 57.1 & 3.0 & 87.4 & 100.0 & 31.0 \\
\hline & & Calanus finmarchicus & 25.0 & 28.5 & 1.1 & 4.2 & 100.0 & 1.5 \\
\hline
\end{tabular}


and that this occurs immediately after they start actively seeking for food. EINARSSON (1960) noticed also smaller larvae of Sebastes marinus swallowed surprisingly larger food items. This may in a way suggest that the larvae are more active than are supposed. In view of these food habits it seems that the larvae are gulping food animals singly.

The contents of stomachs of the migrating juvenile caught by the filter nets in the Kasaoka region were examined individually and the results were summarized in Tables 6-7. Differences in composition of food were apparently associated with the size of the juvenile. For the smaller juvenile Paracalanus parvus predominated in the contents of stomachs, whereas in the larger juvenile three copepods of Paracalanus parvus, Acartia clausi and Centropages abdominalis tended to occur approximately in equall proportion, or Centropages abdominalis tended to form most important part in their diet. When the diet of the juvenile of same size group are compared for different days of collection, the similar trend of variations is seen. In the earlier season food item of major importance was Paracalanus parvus and later Centropages abdominalis made up the higher percentage of the diet. Evidently the larger food animals are taken as the juvenile grow larger. The similar has been observed by Einarsson (1960) and he has suggested a preference for food items of similar size. As little or no other animals other than copepods nor plants have been found in the stomachs in any significant numbers, it appears that the food of juvenile Sebastes inermis is undoubtedly specialized and concentrated to copepods.

There was a remarkable difference between the early morning and the afternoon diet (Table 7). The majority of the juvenile caught in early morning ate very little food and many empty stomachs were found for early morning specimens, whereas the stomachs of afternoon specimens had always some contents. Percentages of occurrence of each food copepods in the diet were incidentally smaller for the former than for the latter. There were also considerable differences in the average numbers of food copepods per stomach between the early morning and the afternoon materials, and the latter exhibited higher numbers. These may be the evidence that the juvenile are not feeding during night but are foraging by day.

Besides these four copepods the following animals were found in the stomachs of the juvenile, namely Oithona similis, Oithona sp., Corycaeus spp., copepodids, Podon sp., mysids, and macruran mysis larvae.

In spite of prevailing food preferences in larval fishes, as has been shown, for example, by Einarsson (1960) for Sebastes marinus fry, it is also well known that the larvae may be sufficed with different kind of food to some extent. For the diet of plaice larvae, for instance, Shelbourne (1957) writes "In the absence of vulnerable animal food in January, the larvae ate plants only," but he questions the value of plant food by saying "If sufficiently abundant, the large thin- 
walled diatoms, e.g. Biddulphia and Coscinodiscus, may help sustain larvae in the transition stage; when scarce, as in January, the energy expended during foraging activitiy may not be balanced by the calorific value of the plants eaten." As has been mentioned above, this kind of change in food does not occur in Sebastes inermis.

The pelagic copepods also played the important part in the diet of juvenile Sebastes oblongus and their composition was roughly same to that of juvenile Sebastes inermis. The juvenile of Hexagrammos otakii and Agrammus agrammus caught with the filter nets together with juvenile Sebastes inermis utilized almost exclusively the larger pelagic copepods. Above all, the larvae of sand-lance, Ammodytes personatus, which were drifting and migrating pelagically in enormous quantities over the area in early spring, were taking pelagic copepods in the early stage and should be the first food competitor to juvenile Sebastes inermis, although they were rather smaller eater than the latter. The amount of principal food copepods of these fishes in number outside in the surrounding waters was roughly calculated to range between 300 and 600 per cubic metre in those areas where fish larvae were gathering to, and this was nearly enough for sufficing them. This means that in some other areas food might be scarce to result in their migration.

(2) The food of the young and adult in relation to the phytal animals

The food of the young and adult black rockfish has been investigated and reported fairly well (FUSE et al., 1956 ; KitAMORI and KOBAyASHI, 1958; KITAMORI, Nagata and Kobayashi, 1959; Fuse et al., 1959; Hatanaka and Iizuka, $1962 a$, $b, c$; FUSE, $1962 a, b)$.

The Zostera belt is regarded as a harbouring and feeding ground of young black rockfish. The food of them was primarily crustaceans, and those items occurring high in number and volume were amphipods, isopods and mysids. The similar food habits have been described by KITAMORI and KOBAYASHI (1958), Kitamori, Nagata and Kobayashi (1959), Hatanaka and Iizuka (1962a) and FUSE (1962 $a$ ) in details. FUSE (1962 $a$ ) observed the evident change-over of the diet from caprellids and gammarids to small shrimps as the former food animals became scarce and the latter increased in the environment, which has been mentioned in the earlier section.

In contrast, when the young were small and entering into the Zostera belt, the pelagic copepods were utilized by them to form the major part of their diet. Kitamori, Nagata and Kobayashi (1959) writes that amphipods and macruran and brachyuran larvae are predominating in the contents of stomachs of black rockfish in the Zostera belt, although in the early young stage copepods are eaten. From the data presented by FUSE (1962a) it is evident that young Sebastes inermis depends its food on copepods to a considerable extent.

The black rockfish of about 6 to $8 \mathrm{~cm}$ were caught at the Sakai Channel by 
the filter nets. These fishes consumed amphipods and isopods, for example, Jassa falcata (MonTAGU) and Ischyrocerus sp., which were not particularly associated with the submerged vegetations, as well as bottom-living shrimps such as Crangon affinis (DE HAAN). In this stage of life, Sebastes inermis is not feeding on pelagic copepods, yet it is a debatable point whether those food animals were eaten on on the substratum or were bolted when they were swimming.

The principal food of adult black rockfish were small crustaceans and polychaetes which were living on the submerged plants such as Sargassum and Zostera and on rocks. The food of the adult has also been shown by HATANAKA and IrzUKA (1962b) and Fuse (1962 b) as phytal animals. The seasonal variations in amount and composition of phytal animals in the Kasaoka region are already shown in Fig. 7 and Table 2. The amphipods and small shrimps as well as snails are abundant and the adult fed on them during most part of the year. Occasionally the mysids were found in the stomachs of adult black rockfish and this, for instance, was observed in the specimens captured at St. 102 in summer when the phytal amphipods were becoming very scarce. In the Naka-no-umi region, too, the amphipods were the dominant phytal animals (Table 3 ), and they formed the major food for Sebastes inermis, though of ten polychaetes, chaetognaths and even small sardinoid fishes were utilized.

The available evidence indicates that the feeding ground of young and adult black rockfish is not strictly confined to the submerged vegetations and the habit of feeding on pelagic animals is retained in the adult stage for some part.

The food of Sebastes oblongus and Sebastiscus marmoratus are somewhat different. Examination of contents of stomachs collected in the Naka-no-umi region revealed that they were comparatively similar in food habit and the major food items were fishes, prawns, crabs and large isopods. The difference between these food items and that of Sebastes inermis is apparent, which appears to be related to the differences in habitats, morphology of gill rakers and behaviour between these fishes.

(3) The food and the structure of gill rakers and digestive canal

The successive changes in the morphology of gill rakers have been already mentioned in the previous section and are summarized in Fig. 26. It is quite remarkable that the late fry larva of $7.1 \mathrm{~mm}$ eats the same food animal, Paracalanus parvus, as the juvenile and young in the submerged vegetations. The gill rakers are not developed well in the late fry stage. They spaced at the intervals of $0.05 \mathrm{~mm}$ approximately and the longest raker measures only $0.08 \mathrm{~mm}$. These gill rakers might be able to sieve much smaller organisms than Paracalanus parvus. The gill rakers attain the full complement by the late migrating juvenile stage and are slender and narrowly arranged. Nevertheless, the diet are almost purely copepods and very few smaller animals are eaten, which are sufficiently large to be filtered up by gill rakers. 
EINARSON (1960) writes for Sebastes marinus “... the gill-rakers $\cdots$ begin developing $\cdots$ and this enables larvae up to a size of $30 \mathrm{~mm}$. to retain their ability to filter feed," but, as has been indicated, larval and juvenile Sebastes inermis is selectively gulping food organisms. Yasuda (1960c) states "The cleft size determines the trapping mechanism or action and the mouth breadth controls the size of prey." The mouth cleft of late fry larvae of Sebastes inermis appears to be just large enough for Paracalanus parvus. YASUdA (1960b) shows also the close relationship between the gill structure and feeding habit and the changes in feeding habit associated with the progress of growth for plankton feeders.

As has been mentioned elsewhere, the diet of Sebastes oblonguis differs from that of Sebastes inermis in the adult stage. Generally, Sebastes oblongus feeds on larger food animals than Sebastes inermis does. Gill rakers of Sebastes oblongus are short and stumpy and not so developed as in Sebastes inermis. On the other hand, in the younger stage, Sebastes oblongus too has as well developed gill rakers as in Sebastes inermis and is utilizing similar food animals. It is eventually obvious that the changes in diet are associated closely with the morphological development of gill rakers.

\begin{tabular}{|c|c|c|c|c|c|c|c|c|}
\hline & Locality & St. 102 & St. 200 & \multicolumn{4}{|c|}{ North of Shiraishi-shima } & \\
\hline & $\mathrm{Do}+\mathrm{e}$ & $\begin{array}{r}\text { Feb. } 22 \\
1958 \\
\end{array}$ & $\begin{array}{r}\text { Feb. } 14 \\
+958 \\
\end{array}$ & \multicolumn{3}{|c|}{ March 4, 1958} & \multicolumn{2}{|c|}{ April 7,1958} \\
\hline \multicolumn{2}{|r|}{ Body Length (mms.) } & 4.0 & 7.1 & 10.5 & 14.5 & 19.3 & 21.5 & 25.7 \\
\hline \multicolumn{2}{|r|}{$\begin{array}{c}\text { Numbers } \\
\text { of } \\
\text { Gill Rakers }\end{array}$} & 0 & 12 & 19 & 21 & 24 & 24 & 25 \\
\hline \multicolumn{2}{|r|}{ Digestive Canol } & & & & & & & \\
\hline \multirow{2}{*}{ 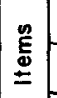 } & Paracalanus parvus & 0 & 2 & 2 & 16 & 26 & 0 & 2 \\
\hline & Acartio clausi & 0 & 0 & 1 & 0 & 0 & 0 & 1 \\
\hline \multirow{2}{*}{ 울 } & Centropages abdominalis & 0 & 0 & 0 & 0 & 0 & 47 & 37 \\
\hline & Calonus finmarchicus & 0 & 0 & 1 & 1 & 4 & 1 & 0 \\
\hline
\end{tabular}

Fig. 26. Development of gill rakers and digestive canal in diagramatic view for juvenile Sebastes inermis. Actual contents of stomachs are also shown.

The development and differentiation of the digestive organ are directional and are nearly completed by the end of the juvenile stage. The expansion of the stomach proceeds in apparent parallelism with the increase in number of organisms in the diet. 


\section{Behaviour}

\section{(1) Activity}

It has been elucidated in the earlier section that the commercial landings of black rockfish fall considerably in summer and that the young in the Zostera belt almost disappear from there by September. The regular underwater observations by diving were undertaken to determine whether the black rockfish were migrating to somewhere from these areas in summer.

The underwater rock crevices at St. 102 and surrounding rocks were chosen for this purpose and were visited once or twice a month. This diving station was located close to an islet and the rocks were extending from its shore down to the muddy bottom of $20 \mathrm{~m}$ in depth. Most of the black rockfish were observed in rock crevices and underneath boulders and the population did not vary much throughout a year. Occasionally, especially in June and November, the adult were observed moving on shoals along the rocks, while the young were aggregating above and along the rocks and boulders. In rock crevices the adult usually took the posture of looking up aslant, but they were not doing this in a unanimous direction and appeared indifferent to each other. In no occasion they seemed to be feeding actively in rock crevices. FUSE (1962 b) has reported that the stomachs of black rockfish caught in summer are often empty, whereas those in winter contain a good quantity of food. The fluctuation of catches of black rockfish by the guiding barriers in the Naka-no-umi region postulates that the fish is active in winter (Fig. 27).

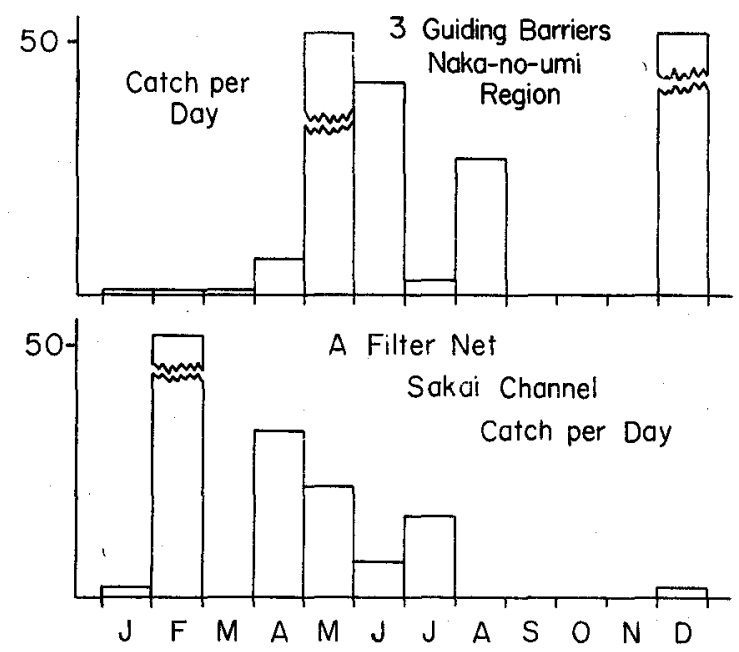

Fig. 27. Catches of Sebastes inermis by guiding barriers and filter net in the Naka-no-umi region. 
In July and December, the underwater observations were made during a whole day to know diurnal changes in ecology of Sebastes inermis. On both occasions, it was observed that most of the adult evacuated rock crevices in evening and were back again in morning. It seems likely that they are foraging during night.

The diurnal variations of catches of black rockfish by the guiding barriers

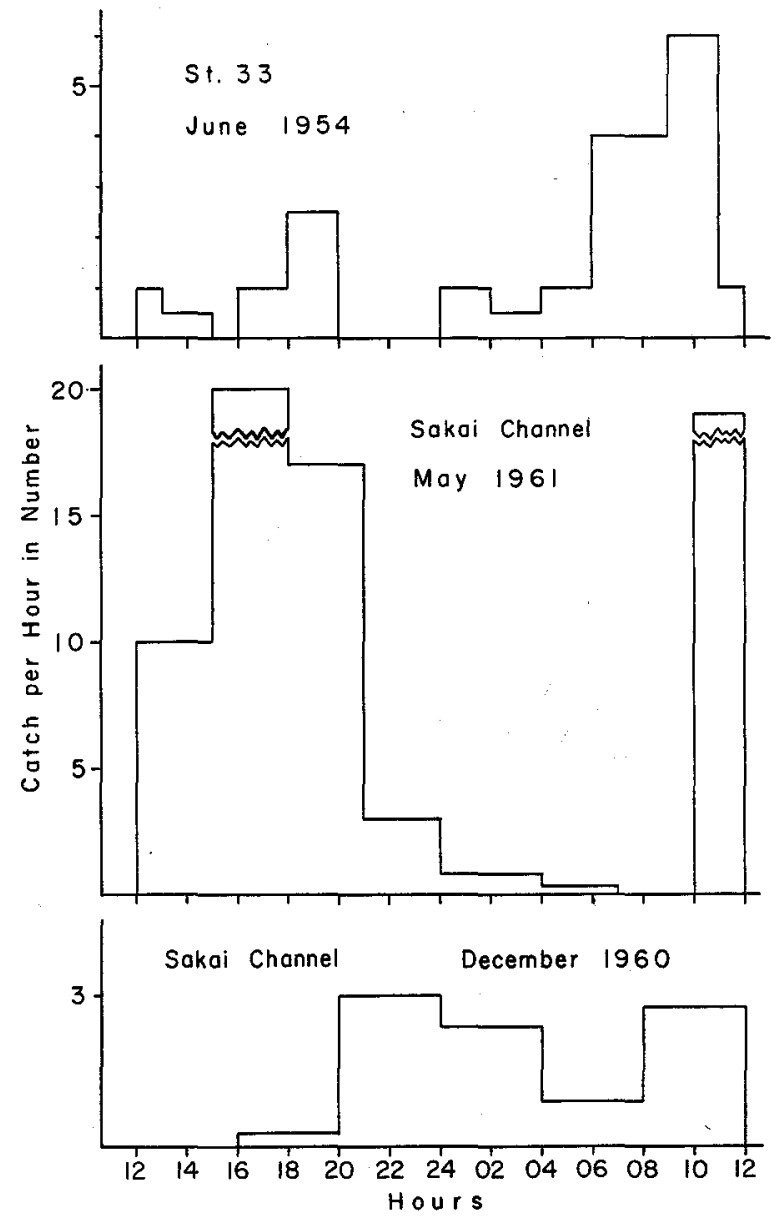

Fig. 28. Diurnal fluctuations of catches of Sebastes inermis by the guiding barriers in the Kasaoka and Nakano-umi regions.

is evident. Three histograms in Fig. 28 appear to have different patterns, but if they are analysed in view of day and night variation, it will be noticed that in upper two figures their peak catches are in the daytime and in the lower the concentration of catches is in night. The majority of catches of the upper two 
in early summer were the young and that of the lower in winter were the adult.

As has been discussed in the previous section, the migrating juvenile are feeding mostly by day. It is, therefore, concluded that Sebastes inermis is active by day in the younger stage and by night in the adult stage, showing distinct change in activity in the course of growth.

\section{(2) Migration}

The disappearance of the young black rockfish from the Zostera belt in summer and their consistent presence in the Sargassum belt suggest that the young migrate from the Zostera belt to the Sargassum belt. The seasonal variations of catches of black rockfish by the guiding barriers and filter net are shown in Fig. 28. A high number recorded by the filter net in February was of the migrating juvenile. There were another two peaks. The catches in summer comprised almost exclusively the young that were presumably migrating to the rocky area from the Zostera belts. A large number of adult black rockfish caught in December formed the third peak and this is due to the activity of the fish in breeding season. Accordingly there seem to be three migrating seasons in Sebastes inermis, although these migrations are different in nature and in extent.

\section{(3) Schooling}

The black rockfish usually do not form a large shoal and, if a shoal is formed, it is by no means of the same nature as, for instance, that of the anchovy or horse mackerel. OKuno (1956) distinguished different types of schooling in reef fishes and KAWANABE (1957) proposed five kinds of fashion in social behaviour for a freshwater fish Plecoglossus altivelis Temminck et SCHLEgel. The shoal of Sebastes inermis is in its nature in the state of "aggregating" of OKuno's proposition. The adult in rock crevices were noticed to come out from there in night, but it is not certain whether they were moving on shoals or not.

In the younger stages, however, the shoal of black rockfish tends to assume the features of school, having all members swimming in the same direction in accord.

It seems probable that the adult are rather solitary, for their habitats are strongly associated with minor topography and are unfavourable for them to aggregate in large number. On the contrary, in the younger stages they are utilizing open water much more, which seems to benefit them to cruise on shoals, and presumably this schooling behaviour is related to the feeding habit as well.

\section{Discussion}

- The life history of Sebastes inermis and its relation to the community-

So far in the preceding discussions various aspects of life of Sebastes inermis, 
if not over-all and thorough but perhaps of skeleton features, have been dealt with under separate headings. These series of events are by no means simply occurring simultaneously but are affecting each other with varying importance and in various ways as the animal grows. The life history is not a mere sequence of events occurring irrespectively and spontaneously. It is a series of progressive phases evolving one after another by bringing forth new demands of life and resolving them. Assumably, in a phase of life the morphological characters would have ruling control over other requirements and then in the next food habits might play the leading role in determining the way of life. As the result of interactions of various factors and demands renewing inherently with growth of the animal, the fundamental and rather abrupt changes of life have to be effected, by which the whole course of life is divided into more or less stable phases or the developmental stages.

Shibuya $(1956,1961)$ has emphasized the importance of recognizing the developmental stage and life history for an understanding of the mode of life of organisms both at the individual or species level and in synecological bearings, as it is to be established through whole course of life. Intrinsic significance of progressive phases in the life history of an animal has also been assessed recently by VASNETSOV and others (1957). They have studied fish on this line and have proposed a certain number of post-larval stages. These stages are defined principally by the differences in morphology, specially of the internal organs and structure, in relation to ecological difference such as those in habitat, behaviour and food. Although they have proposed the finer staging for their fishes, the life history of Sebastes inermis seems to be best understood ecologically by dividing it into the following five major stages after emergination. These might be eventually distinguished by size for convenience's sake, and perhaps might not differ so much from the conventional staging.

1. Palagic inaptly-feeding fry

2. Pelagic plankton-feeding fry

3. Pelagic migrating juvenile

4. Settling young

5. Adult

The first stage must be very short as the larvae are liberated in a fairly well-developed form. No direct observations are available concerning growth in this stage for Sebastes inermis, but FujITA (1957) gave a length increment of $2.85 \mathrm{~mm}$ in 20 days for a larva of $6.9 \mathrm{~mm}$ of Sebastes bachycephalus nigricans, and the first stage of Sebastes inermis could be assessed to last for a mouth at longest. Since the larvae have little ability to swim and are not feeding actively, their movement and dispersal are largely depending on hydrological conditions of the area. In this and next stages they may be preyed upon comparatively heavily as larger carnivorous plankton organisms are increasing in this season. 
In the second stage the larvae start feeding actively and increasingly as the differentiation of digestive organ progresses. Although the gill rakers are only poorly developed, this may not be so significant for feeding, since the principal food is pelagic copepods consistently until the early fourth stage and the larvae are taking them apparently by gulping but not by filtering. YASUDA (1960) has attributed the similar feeding habit even for the younger stages of planktonfeeding fishes. The development of fins is still poor and so the chance of encountering food organisms must be the essential requirement, which is favoured apparently by the increase of food copepods in the midwater layers at this time of the year.

In the third stage nearly all morphological developments are completed and the juvenile tend to descend to the bottom layer and gradually migrate toward the shore. The diet pelagic copepod varies according to size of the larvae. Their concentration on the straits might have two ecological meanings, the movemen of water and the especially rich food supply, though there is generally abundant presence of food plankton organisms over the whole area at this time.

The young in the fourth stage retain preceding food habits for sometime after their invasion into the submerged vegetations, and then the change-over of principal food takes place from pelagic copepods to phytal animals occurring abundantly there. In this stage they may at first show schooling behaviour, particularly when they are cruising around over the vegetations for food copepods, but later they tend to shelter themselves individually by the plant growth, probably at this time feeding much on phytal animals.

The last stage is the long and stable one spent in the rocky area. They primary importance of this stage is to secure sheltering rock crevices or holes. Still their way of living is not so much associated with sheltering place or bottom in such a degree that Sebastiscus marmoratus is. Occasionally they are feeding on large plankton animals, for which purpose their slender gill rakers are obviously beneficial.

As to Sebastes marinus larvae Templeman (1959) writes "They have a pelagic life of at least several months in upper water layers." STEELE (1957) also suggests that the redfish larvae live near the surface. If the third stage could be included, the pelagic life of Sebastes inermis would be said to last at least two months. However, the third stage can not be regarded as a surface pelagic life. In this respect Sebastes inermis differs distinctly from Sebastes marinus in larval life, and this is due to the difference in the mode of life of the adult; the former is inhabiting the coastal area, while the latter the oceanic waters.

Although the early larvae are vulnerable, taking into account the abundance in the following stages and viviparity of the species, the mortality in the initial stage may not be so high, and the food situations outside during larval stages seem to be generally favourable. HJORT (1926) has paid much attention to 
mortality in the early life history of fish and, by seeking the most critical period in the very earliest larval and young fry stages, ascribed to it two factors of lack of proper food immediately after yolk absorption and offshore drift. It is not likely the case with Sebastes inermis, however, that the former event is seriously occurring, and thus it is believed that survival curve of the larvae is not of the type of MARR's (1956) critical period model.

Concerning the critical period in the early life history, Shelbourne (1957) deduces that the famine induces loss of osmotic control in plaice larvae resulting in local high mortality. BisHaI (1961) shows good salinity tolerance in larvae of salmon, herring and plaice, and indicates the important role of feeding condition and nature of food in it. YокотA et al. (1961) conclude from their observations on the diet and digestive canal of larvae of marine fishes and plankton in the environments that disastrous high mortality of early fry larvae may not occur from local scarcity of food in the natal ground only, but the competition and predation in the nursery ground are much more serious. They also show apparent size-preference for food and its changes with growth in the fishes they observed. As has been mentioned previously, predation by large voracious plankton animals such as Sagitta may affect survival of pelagic black rock fish larvae as well as benthic carnivorous fishes do on the migrating juvenile of the same fish. It appears to be correct that, in his discussion on the critical period of fish, PEARCY (1962) states "There is little evidence, however, in support of his (HJORT's) supposition that the size of a year-class is determined during any single larval phases. It seems more plausible that mortality, which is a combination of density-dependent and density-independent variables, is important throughout the entire early life history. ... This suggests that the 'critical period' concept is equivocal and oversimplified. It is of limited value since it tells little about the causes, distribution, or rates of mortality."

A basic trend seen in the life history of Sebastes inermis is the gradual specialization of its habitat. It starts from the open sea, then to the level bottom of the open sea, the coastal bottom, the submerged vegetation and finally terminates in the rock crevices. For these changes of habitat or migrations the food might be supposed to be playing the paramount role. If so, then evidence that the young in the Zostera belt are feeding on pelagic copepods is somewhat irreconcilable. Further, when the phytal animals in the Zostera belts decrease, they are also more or less declining in amount in the Sargassum belts, into which the young leaving the former are supposed to migrate. If the food and habitat of the fish are analysed and considered together, it will become clear that their migration is not induced merely by the food-preference of the fish and the abundance or scarcity of food animals in the environment, but is reflecting the indispensability of specialized regional topography as abiotic habitat at each epoch as well. The similar is shown for the herring by Hourston (1959) who states "It would appear 
that the herring were neither carried across the sound by prevailing currents nor were they simply following their food supply. The fish appear to have dispersed and gradually collected in the sheltered bays, inlets and channels."

HatanakA and IrzUkA (1962 $a, b, c)$ have repeatedly emphasized that in the Zostera belts the food segregation and the ecological order for feeding, measured in terms of the ecological niche of food animals, are noticeable, and that Sebastes inermis, ranked in the middle, is suppressed and diminished by others through limitation of food available. However, it is obvious that the ecological order they proposed in this way has nothing to do with the actual relations between fishes and affords no basis to suppose that the fishes in lower orders are controlled their freedom of food-taking by the highers, for instance Sebastes inermis by Pseudoblennius cottoides. Examination of food animals in the environments reveal that there is a fairly good quantity of phytal animals available for fishes. It is also unlikely that, among fishes of so different habits, the food segregation is caused directly through the paucity of food in the environment and resultant food competition. It must not be denied that fishes utilizing same food organisms in an area hold directly or indirectly some sort of relation each other, but it seems to have gone too far if, simply by this, the difference in food composition of these fishes should be concluded as food segregation through food competition. Apparent segregation of food of fishes might be for some part related to their interaction, but should be much more understood integratively as the reflection of different modes of life as a whole.

The concept of community has been proposed, reviewed and defined by many ecologists (Macfadyen, 1957 ; Shibuya, 1956, 1961 ; Kawanabe, 1960 ; etc.) since the time when MoEbius used the term "biocönoze" for the first time to the oyster bed community, and the modern view emphasizes the complex or the integration of acting interrelations as the essential feature of commnuity unity. Yet it must be kept aware that, in the biological nature, co-existence of organisms both in space and in time is a basic prerequisite to the ecological relationship. Then, how far it should be traced to grasp the whole community? CoLEBRook et al. (1961) write "Because there are so few barriers to their dispersal, pelagic communities are not so easily classified and it is difficult, if not impossible, to use the word 'community' with any precise meaning." If the fishes swiftly moving after food plankton patches from area to area are considered, the plankton community could be so huge from the point of view of the community as the complex of ecological relations between organisms. On the other hand, as has been indicated by HeINRICH (1962), the changes in the plankton community in time are sometimes very well understood in the light of life histories of component organisms. If the full evidence for life histories of component organisms were presented, the picture of a community, the whole of ecological relations between organisms or species, would be too complicated and extended vastly. There is nothing to suppose that the surrounding 
biological worlds of Sebastes inermis in the Zostera and Sagassum belts could be the communities of identical nature, however it should hold overwhelming dominance in these, nor those of the adult and the young. Although Sebastes inermis is occurring in both the Zostera and the Sargassum belt, the ecological meanings of these two phenomena are not exactly identical. It certainly should not be denied that there might be similarities in the basic framework of community unity, and the community structure and function could be brought into a general understanding by the informations of species composition, biological production system and bioeconomic relationship; nevertheless the answer to why and how it is so there should be reached through thorough knowledge of dynamic aspects of life histories of member organisms. The community in existence at present is naturally influenced by those in the past or in neighbouring areas, say the summer Zostera community receiving the legacies from the spring Zostera community. There is community continuity, in which community discontinuity lies. As has been pointed out by WHITTAKER (1957), the community has two aspects of stability and instability, and the interrelation of these two aspects may be accounted for by considering the stableness and rather abrupt change-over of the developmental stages of constituent organisms, particularly of the dominant ones.

\section{Conclusion and Summary}

1. The life history of Sebastes inermis, discussed in the present paper, is tentatively figured in schematic expression as follows (Fig. 29).

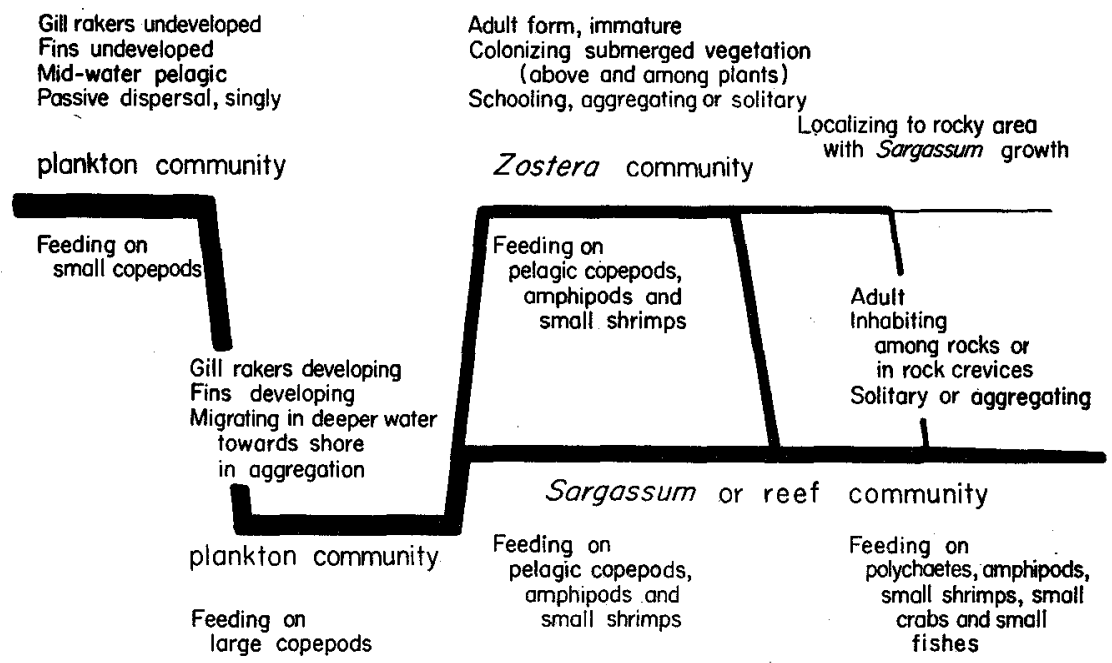

Fig. 29. Schematic representation of events in the life history of Sebastes inermis.

2. The well-developed larvae are extruded from the female parents in winter. Numbers of larvae taken by the tow net reach to their maxima in January in 
the Kasaoka region. The density of pelagic larvae is high in the vicinites of reefs. The juvenile migrate in deeper water and then aggregate toward shores. The young come to settle in the Zostera and Sargassum belts in early spring, but in the adult stage most of them move to the rocky areas and inhabit in rock crevices. Sebastes inermis is not changing the habitat merely in search of food, but is acquiring more specialized life in all aspects at each developmental stage.

3. Sabastes oblongus appears to have the similar course of life history to Sebastes inermis. Contrary to the latter, however, the former comes to the Zostera belt earlier than the latter and much more remain there throughout its life.

4. General morphology of larval to young stages of Sebastes inermis is described and figured.

5. The more or less abrupt changes in the diet occur at several stages of life. Specialization of stomach contents of the juvenile is shown to have two meanings. They feed selectively on particular organisms out of available food organisms and, on the other hand, the diet is regulated by what organisms are available outside. These are clearly understood by taking the morphology of gill rakers and changes in habitat into account in relation to the community they belong. Even the adult feed on large plankton like mysids and they still have long slender gill rakers of filter feeding type, differing in this character remarkably from Sebastes oblongus, Sebastes schlegeli, Sebastes longispinis and Sebastiscus marmoratus. Occasionally small fishes are found in the contents of stomachs of the adult, but the predominating food items are small crustaceans and polychaetes which are abundant in the Sargassum and Zostera belts.

6. In the juvenile and young stages Sebastes inermis is active by day, while the adult are by night and their activity culminates in winter. In the younger stages schooling is more common than in the adult stage, and this may be related to feeding habits.

7. A short discussion is given on the concept of community in view of the life history.

\section{REFERENCE}

ANDREwartha, H. G. and BirCH, L. C. 1954. The Distribution and Abundance of Animals. Univ. Chicago Press, Chicago.

BISHAI, H. M. 1960. The effect of water currents on the survival and distribution of fish larvae. Journ. Cons. int. Explor. Mer, Vol. 25, No. 2, pp. 134-146.

1961. The effect of salinity on the survival and distribution of larval and young

fish. Ibid., Vol. 26, No. 2, pp. 166-179.

BRIDGER, J. P. 1956. On day and night variation in catches of fish larvae. Ibid., Vol. 22, No. 1. pp. $42-57$.

1958. On efficiency tests made with a modified Gulf III high-speed tow-net. Ibid., Vol. 23, No. 3, pp. 357-365.

Colebrook, J. M., Glover, R. S. and Robinson, G. A. 1961. Continuous plankton records : Contributions towards a plankton atlas of the north-eastern Atlantic and the North Sea. General introduction. Bull. Mar. Ecol., Vol. 5, No. 42, pp. 67-80. 
Colman, J. 1939. On the faunas inhabiting intertidal seaweeds. Journ. mar. biol. Assoc., U.K., Vol. 24, No. 1, pp. 129-183.

DiCe, L. R. 1952. Natural Comminities. Univ. Michigan Press, Ann Arbor.

EINARsSON, H. 1960. The fry of Sebastes in Icelandic waters and adjacent seas. Rit Fiskideildar, Vol. 2, No. 7, pp. 3-49, Pls. I-II, Appendix A-C (pp. 52-67).

Elton, Ch. and MLLLER, R. S. 1954. The ecological survey of animal communities: with a practical system of classifying habitats by structural characters. J. Ecol., Vol. 42, pp. 460-496.

FujitA, S. 1957. On the larval stages of a scorpaenid fish, Sebastes pachycephalus nigricans (SchmidT). Jap. J. Ichthy., Vol. 6, Nos. 4-6, pp. 91-93.

FuSE, S. 1962 a. Animal communities in the Zostera belts. Physiol. and Ecol., Vol. 11, No. 1. (in Japanese)

1962 b. Animal communities in the Sargassum belts. Physiol. and Ecol., Vol. 11, No. 1. (in Japanese)

Fuse, S., Habe, T., Harada, E., OKuno, R. and Mura, T. 1959. The animal communities in the submerged marine plant vegetations. Bull. Mar. Biol. Sta. Asamushi, Tohoku Univ., Vol. 9, No. 4, pp. 173-175.

HANSEN, V. K. and ANDERSEN, K. P. 1961. Recent Danish investigations on the distribution of larvae of Sebastes marinus in the North Atlantic. Rapp. Cons. Explor. Mer, No. 150, pp. 201-215.

HATANAKA, M. and IrzUKA, K. 1962a. Studies on the fish community of the Zostera area-I. The ecological order for feeding in the fish group related to the dominant species. Bull. Jap. Soc. Sci. Fish., Vol. 28, No. 1, pp. 5-16. (in Japanese) and 1962b. Studies on the fish community in the Zostera area-II. Trophic order in a fish group living outside of the Zostera area. Ibid., Vol. 28, No. 2, pp. 155161. (in Japanese)

and 1962c. Studies on the fish community in the Zostera area-III. Efficiency of production of Sebastes inermis. Ibid., Vol. 28, No. 3, pp. 305-313. (in Japanese)

HEINRICH, A. K. 1962. The life histories of plankton animals and seasonal cycles of plankton communities in the oceans. Journ. Cons. int. ESlor. Mer, Vol. 27, No. 1, pp. 15-24.

Henderson, G. T. D. 1961a. Continuous plankton records: The distribution of young stages of Sebastes. Rapp. Cons. Explor. Mer, No. 150, pp. 216-219.

1961 b. Continuous plankton records: The distribution of young Sebastes marinus (L.). Bull. Mar. Ecol., Vol. 5, No. 46, pp. 173-193.

HJORT, J. 1926. Fluctuations in the year class of important food fishes. Journ. Cons. int. Explor. Mer, Vol. 1, No. 1, pp. 5-39.

Hourston, S. A. 1959. Effects of some aspects of environment on the distribution of juvenile herring in Barkley Sound. J. Fish. Res. Bd. Canada, Vol. 16, No. 3. pp. 283-308.

INABA, D. 1931. On some teleostean eggs and larvae found in Mutsu Bay. Rec. Oceanogr. Works in Japan, Vol. 3, No. 2, pp. 53-62, Pl. XI (I).

KAto, A. and KurohiJI, Y. 1960. A midwater trawl for collecting juveniles. Rept. Nankai Reg. Fish. Res. Lab., No. 12, pp. 45-51. (in Japanese)

KaWANABE, H. 1957. Social behaviour and production of a salmon-like fish, Plecoglossus altivelis, or Ayu, with reference to its population density. Jap. J. Ecol., Vol. 7, No. 4, pp. 131-137. (in Japanese)

1960. An opinion on the study of the lotic animal community. Physiol. and Ecol., Vol. 9, No. 1, pp. 1-10. (in Japanese)

Kazihara, T., IIzUKa, S. and Tanaka, M. 1958. Studies on the catch by masuami. I. Oceanographic conditions of the fishing ground, net construction and the species in the catch. Bull. Fac. Fish. Nagasaki Univ., No. 6, pp. 113-120. (in Japanese)

KIKUCHI, T. 1961. An ecological study on animal community of Zostera belt, in Tomioka Bay, Amakusa, Kyushu (I). Community composition (1). Fish fauna. Rec. Oceanogr. Works in Japan, N. S., Special No. 5, pp. 211-219, Appendix 1-2.

KITA, T. and HARADA, E. 1962. Studies on the epiphytic communities. 1. The abundance and 
distribution of microalgae and small animals on the Zostera blades. Publ. Seto Mar. Biol. Lab., Vol. 10, No. 2, pp. 245-257.

KITAMORI, R. and Kobayashi, S. 1958. The ecological study on "Moba" (zone of Zostera marine L.). (I) Phase of early summer. Bull. Naikai Reg. Fish. Res. Lab., No. 11, pp. 7-16. (in Japanese)

Kitamori, R., Nagata, K. and Kobayashi, S. 1959. TRe ecological study on "Moba" (zone of Zostera marina L.) (II) Seasonal changes. Ibid., No. 12, pp. 187-199. (in Japanese)

KoBAyAshr, H. 1934. Types of the digestive canal in the fish. Bot. and Zool., Tokyo, Vol. 2, No. 11, pp. 1896-1898. (in Japanese)

LAMBERT, D. G. 1960. The food of the redfish Sebastes marinus (L.) in the Newfoundland area. J. Fish. Res. Bd. Canada, Vol. 17, No. 2, pp. 235-243.

MACFAdyen, A. 1957. Animal Ecology. Aims and Methods. Isaac Pitman and Sons, London.

MARR, J. C. 1956 . The critical period in early life history of marine fishes. Journ. Cons. int. Explor. Mer, Vol. 21, No. 2, pp. 160-171.

Matsubara, K. 1943a. Studies on the scorpaenoid fishes of Japan. Anatomy, phylogeny and taxonomy. (I). Trans. Sigenkagaku Kenkyusho, No. 1, pp. 3-170.

1934b. Studies on the scorpaenoid fishes of Japan. Anatomy, phylogeny and taxonomy. (II). Ibid., No. 2, pp. 171-486, Pls. I-IV.

1955. Pish Morphology and Hierarchy. Ishizaki-shoten, Tokyo. (in Japanese)

MIo, S. 1960a. Biology of Sebastiscus marmoratus CUVIER et VAIENCIENNES. Rec. Oceanogr. Works in Japan, N. S., Vol. 5, No. 2, pp. 77-85.

1960b. Biology of Sebastes inermis CuVIER et VALENCIENNES. Ibid., N. S., Vol. 5, No. 2, pp. 86-97.

- 1961a. Studies on population biology of coastal fishes in Kyushu. I. Biology of Sebastes inermis Cuvier et Valenciennes. Sci. Bull. Fac. Agric. Kyushu Univ., Vol. 18, No. 4, pp. 419-436. (in Japanese)

Mıo, S. 1961b. Studies on population biology of coastal fishes in Kyushu. II. Biology of Sebastiscus marmoratus (Cuvier et VALENCIENNES). Ibid., Vol. 18, No. 4, pp. 437-450. (in Japanese)

MIZUE, K. 1957. Studies on a scorpaenous fish Sebastiscus marmoratus CUVIER et VALENCIENNES. I. Bull. Fac. Fish. Nagasaki Univ., No. 5, pp. 27-29. (in Japanese)

1958a. Studies on a scorpaenous fish Sebastiscus marmoratus CuVIER et VALENCIENNES. II. The seasonal cycle of mature testis and the spermatogenesis. Ibid., No. 6, pp. 27-38. (in Japanese)

1958b. Studies on a scorpaenous fish Sebastiscus marmoratus CuviER et Valenciennes. III. On the annulus of otolith and the growth. Ibid., No. 7, pp. 1-9. (in Japanese)

1959a. Studies on a scorpaenous fish Sebastiscus marmoratus CuVIER et VALENCIENNES.

IV. On the copulatory organ of the marine ovoviviparous teleost. Ibid., No. 8, pp. 80-83, Pl. I. (in Japanese)

1959b. Studies on a scorpaenous fish Sebastiscus marmoratus CuviER et VALENCIENNEs. V. On the maturation and the seasonal cycle of the ovaries of the marine ovoviviparous teleost. Ibid., No. 8, pp. 84-110, Appendix Tables I-II, Pls. II-XIII. (in Japanese)

$1959 c$. About the seasonal cycle of mature testis of Sebastes inermis. Ibid., No. 8, pp. 111-122, P!s. XIV-XV. (in Japanese)

Moore, H. B. 1958. Marine Ecology. John Wiley and Sons, New York.

Murakami, A. 1954. Oceanography of Kasaoka Bay in the Seto Inland Sea. Bull. Naikai Reg. Fish. Res. Lab., No. 6, pp. 15-57. (in Japanese)

NAKAMURA, S. 1934. Larval and juvenile stages of reef fishes occurring in the adjacent waters of Kominato (V-VI). Yoshoku-kaishi, Vol. 4, Nos. 7-8, pp. 121-132. (in Japanese)

1936. Larval and juvenile stages of reef fishes occurring in the adjacent waters of Kominato (XIV). Ibid., Vol. 6, Nos. 7-8, pp. 133-139. (in Japanese)

OHshima, Y. 1954. On the Zostera belt and conservation of juvenile fishes. Review of Fisheries Science in Japan (Suisangaku-no-gaikan), pp. 128-166, Appendix pp. 166-181. (in Japanese)

Okuno, R. 1956. Modes of life of some reef fishes with references to their microhabitats, food habits and social behąviors. Contr. Physiol. Ecol. Kyoto Univ., No. 80, pp. 1-15. (in Japanese) 
Pearcy, W. G. 1962. Ecology of an estuarine population of winter flounder, Pseudopleuronectes americanus (WALbaum). Part III. Distribution, abundance, growth and production of juveniles; survival of larvae and juveniles. Bull. Bingham Oceanogr. Collection, Vol. 18, Article 1, pp. 39-64.

Petersen, C. G. Joh. 1911. Valuation of the sea. I. Animal life of the sea bottom, its food and quantity. Rep. Danish biol. Sta., No. 20, pp. 1-73.

1918. The sea bottom and its production of fish-food. Ibid., No. 25, pp. 1-57.

Research Group on Marine Ecology, Kyoto Univ. (FuSE, S., MiYadi, D., Habe, T., MiURA, T., OKuNO, R. and HARADA, E.). 1956. Habitats with relation to developmental stages of fishes in the bays. VIIth Symposium in Biological Science on "Interrelation between Organisms and their Environments" (Osaka, 1955). Biological Science, Tokyo, Separate Vol., pp. 68-71. (in Japanese)

Schamardina, I. P. 1957. The developmental stages of Esox lucius. Trud. Inst. Morph. Zivot. A. N. Severtsov, No. 16, pp. 237-298. (in Russian)

Shelbourne, J. E. 1957. The feeding and condition of plaice larvae in good and bad plankton patches. J. mar. biol. Assoc., U. K., Vol. 36, No. 3, pp. 539-552.

ShibUy A, H. 1956. Problems in Ecology. Rironsha, Tokyo. (in Japanese)

1961. Theoretical Ecology. Rironsha, Tokyo. (in Japanese)

Siokawa, T. and Tsukahara, H. 1961. Studies on habits of coastal fishes in the Amakusa Islands. Part I. Early life history of the purple rockfish, Sebastes pachycephalus pachycephalus Temminck et Schlegel. Rec. Oceanogr. Works in Japan, N. S., Special No. 5, pp. 123-127.

STEELE, D. H. 1957. The redfish (Sebastes marinus L.) in the western Gulf of St. Lawrence. J. Fish. Res. Bd. Canada, Vol. 14, No. 6, pp. 899-924.

TÅING, A. V. 1949. On the breeding places and abundance of redfish (Sebastes) in the North Atlantic. Journ. Cons. int. Explor. Mer, Vol. 16, No. 1, pp. 85-95.

Templeman, W. 1959. Redfish distribution in the North Atlantic. Fish. Res. Bd. Canada, Bull. No. 120, pp. 1-173, Figs. 1-4.

Templeman, W. and SANDEMAN, E. J. 1959. Variations in caudal pigmentation in late-stage pre-extrusion larvae from marinus- and metella-type female redfish from the Newfoundland area. J. Fish. Res. Bd. Canada, Vol. 16, No. 6, pp. 763-781, Plates and Explanations pp. 783-789.

Thompson, D'Arcy W. 1942. On Growth and Form. Macmillan, New York.

UchidA, K. 1943. Review on the life history of fish. Kaiyo-no-kagaku, Vol. 3, No. 10, pp. 1-9. (in Japanese)

Uchida, K., Imai, S., Mito, S., Fujita, S., Ueno, M., Shojima, Y., Senta, T., Tahuku, M. and DotU, Y. 1958. Studies on eggs, larvae and juvenile of Japanese fishes. Series I. Second Lab. Fish. Biol., Fish. Dept. Fac. Agric., Kyushu Univ., Fukuoka. 89 pp., Pls. 1-86. (in Japanese)

Vasnetsov, V. V., Eremeeva, E. F., Lange, N. O., Dmitrieva, E. N. and Braginskaya, R. Y. 1957. The developmental stages of productive semi-anadromous and semi-catadromous fishes of Volga and Don-Abramis brama, Cyprinus carpio, Rutilus rutilus caspicus, Rutilus rutilus heckeli and Lucioperca lucioperca. Trud. Inst. Morph. Zivot. A. N. Severtsov, No. 16, pp. 7-76. (in Russian)

WhitTAKER, R. H. 1957. Evolution of ecological concepts in relation to the eastern forests of North America. Amer. J. Bot., Vol. 44, pp. 197-206.

YAsudA, F. 1960a. The feeding mechanism in young fishes. Rec. Oceanogr. Works in Japan, N. S., Vol. 5, No. 2, pp. 132-138.

$1960 \mathrm{~b}$. The relationship of the gill structure and food habits of some coastal fishes in Japan. Ibid., N. S., Vol. 5, No. 2, pp. 139-152.

1960c. The feeding mechanism in some carnivorous fishes. Ibid., N. S., Vol. 5, No. 2, pp. $153-160$.

YAsudA, F. and Hiy AmA, Y. 1957. Mechanism of utilization of plankton by some fishes. Ibid, N. S., Vol. 3, No. 1, pp. 85-91.

and

1959. A measure of role of utilization of plankton-feeders by carnivorous fishes in a certain area. Ibid., N. S., Vol. 5, No. 1, pp. 85-90.

Yokota, T., Toriyama, M., KanaI, F. and Nomura, S. 1961. Studies on the feeding habit of fishes. Rept. Nankai Reg. Fish. Res. Lab., No. 14, pp. 1-234. (in Japanese) 